\title{
The equity-like behaviour of sovereign bonds
}

\section{Article}

\section{Accepted Version}

Creative Commons: Attribution-Noncommercial-No Derivative Works 4.0

Dufour, A., Stancu, A. and Varotto, S. (2017) The equity-like behaviour of sovereign bonds. Journal of International Financial Markets, Institutions and Money, 48. pp. 25-46. ISSN 1042-4431 doi: https://doi.org/10.1016/j.intfin.2016.11.014 Available at https://centaur.reading.ac.uk/68187/

It is advisable to refer to the publisher's version if you intend to cite from the work. See Guidance on citing.

To link to this article DOI: http://dx.doi.org/10.1016/j.intfin.2016.11.014

Publisher: Elsevier

All outputs in CentAUR are protected by Intellectual Property Rights law, including copyright law. Copyright and IPR is retained by the creators or other copyright holders. Terms and conditions for use of this material are defined in the End User Agreement.

\section{www.reading.ac.uk/centaur}

\section{CentAUR}

Central Archive at the University of Reading

Reading's research outputs online 


\title{
The Equity-like Behaviour of Sovereign Bonds
}

\author{
Alfonso Dufour ${ }^{\S}$, Andrei Stancu ${ }^{\ddagger}$, Simone Varotto ${ }^{\S}$
}

\begin{abstract}
Using a rich dataset of high frequency historical information from 2004 to 2013 we study the determinants of European sovereign bond returns over calm and crisis periods. We find that the sign of the equity beta crucially depends on country risk. In low risk countries, government bonds represent a natural hedge against equity risk as the equity beta is negative regardless of market conditions. On the other hand, government bonds of high risk countries lose their "safe-asset" status and exhibit more equity-like behaviour during the sovereign debt crisis, with positive and strongly significant co-movements relative to the stock market. Our estimates indicate that the equity beta switches from negative to positive when a sovereign's credit spread rises above $2 \%$. We find that the decoupling of the government bond market between high risk and low risk countries implies that indiscriminate portfolio diversification does not pay. Instead, "prudent diversification" appears to offer superior risk adjusted returns in periods of sovereign stress and through the economic cycle.
\end{abstract}

JEL Classification: G01, G12, G15, E43

Keywords: Government Bonds, Stock-Bond Co-movements, Subprime Crisis, Sovereign Debt Crisis, Credit Risk, Liquidity Risk.

\footnotetext{
$\S$ ICMA Centre, Henley Business School, University of Reading, Reading, RG6 6BA, United Kingdom. Email: a.dufour@icmacentre.ac.uk (A. Dufour), s.varotto@icmacentre.ac.uk (S. Varotto, corresponding author). ${ }^{\ddagger}$ Norwich Business School, University of East Anglia, Norwich Research Park, Norwich, NR4 7TJ, United Kingdom. Email: a.stancu@uea.ac.uk (A. Stancu).
} 


\section{Introduction}

Common distinctions between "safe" and "risky" assets have been called into question following the Great Recession that affected global markets after 2007. The abnormally high credit spreads observed for a number of government securities in developed economies, previously considered virtually riskless, mark a paradigm shift in investors' perceptions with profound implications for pricing, hedging and portfolio allocation strategies. The 2010-13 European sovereign debt crisis offers the perfect setting to analyse the determinants of government bond returns and to study how the importance of these determinants changes over time. Specifically, an equity risk factor has long been used in the finance literature to explain government bond returns (Fama and French, 1993). It is well documented that, in crisis periods, government bonds and stocks exhibit negative co-movements, which result in a negative beta for the equity risk factor. When uncertainty is high, investors migrate away from stock markets and buy government bonds which are perceived to be safer (Connolly et al., 2005). However, with higher levels of sovereign default risk this flight-to-safety behaviour is no longer justified.

We contribute to the literature in a number of ways. First, so far researchers have focused on a macro narrative to explain sign changes in stock-bond correlation over time (Campbell et al., 2016; David and Veronesi, 2013; Burkhardt and Hasseltoft, 2012; Ermolov, 2015; Song, 2016). We offer another interpretative angle and conclude that stock-bond co-movements respond to the level of sovereign credit risk. This measure complements the existing macrointerpretation as the level of sovereign risk can be seen as a synthesis of the factors that affect the sovereign's macroeconomic profile (Gapen et al., 2008 and Gray et al., 2007). However, we show that this measure can prove more effective than key macro-variables at capturing the switch in sign of stock-bond correlations observed during the sovereign crisis. It could also prove particularly useful in countries where readily available macro-indicators are few. Figure I gives a stylized description of our findings. We observe that the correlation between stock and government bond returns becomes positive for high risk countries at the start of the sovereign debt crisis. This suggests that bonds issued by governments with a poor credit profile behave more like equities rather than safe assets when economic conditions deteriorate. Specifically, we find that the critical threshold for the stock-bond correlation to switch sign occurs when sovereign credit spreads go beyond $2 \%$. 
Campbell et al. (2015) provide further insights into stock-bond covariation and suggest that the monetary policy stance, in addition to macro-economic shocks, can be a contributing factor in the US market. However, interest rate policy cannot be a driving factor of the sign switch of stock-bond correlation within the Eurozone. This is because all the countries in the Eurozone are subject to the same central bank decisions, while the sign switch only occurs in a sub-group of these countries, that is, those with high sovereign risk. Hau and Lai (2016) point out that a common monetary policy in the Eurozone can still generate different asset allocation incentives in member countries due to differences in real rates. This is because of divergence in local inflation among Eurozone countries. When we control for local inflation levels we still find that sovereign risk is an important factor to explain stock-bond comovements in high risk countries.

Further, in response to the crisis, the European Central Bank (ECB) has used unconventional monetary policy measures (quantitative easing or $\mathrm{QE}$ ) to boost government bond markets via direct bond purchases (Eser and Schwaab, 2016). QE would often lead to a positive stock market reaction. The resulting upward pressure in both stock and bond prices could contribute to positive stock-bond correlation. The evidence, however, rules out this explanation. Instead of observing positive stock and bond market returns in high risk countries during the first part of the sovereign crisis when stock-bond correlation turns positive, we see mostly negative returns in both markets.

Our sovereign risk argument finds indirect support in the findings of Weigel and Gemmill (2006) who observe a positive relationship between stock markets and the distance to default of emerging economies. The implication is that in the countries with relatively high risk in their sample (Argentina, Brazil, Venezuela and Mexico) an increase in country risk and government bond yields leads to a fall in stocks. This generates a positive stock-bond relationship. Similar findings are obtained from a larger sample of emerging economies by Longstaff et al. (2011). An explanation of this positive relationship could come from the sovereign ceiling channel described by Almeida et al. (2016) whereby sovereign rating downgrades, resulting in lower bond prices, generate a deterioration of credit quality across the private sector (i.e. lower stock prices). ${ }^{1} \mathrm{~A}$ similar impact on stock and bond prices would

\footnotetext{
${ }^{1}$ The positive relationship between the level of credit risk and the level of stock-bond correlation was also observed in the US corporate bond market. Blume et al. (1991) report a strong positive correlation between S\&P500 stocks and high-yield corporate bonds (.52) during the 1980s. Investment grade and sovereign bonds
} 
also be reached when it is the private sector that produces negative spillovers on the government's creditworthiness. For instance, higher corporate default can bring about lower tax revenue and onerous bailout packages that can have serious consequences for public finances and sovereign default risk. ${ }^{2}$ Acharya et al. (2014) illustrate this point in the context of the Great Recession and bank bailouts.

As a second contribution, our work documents a departure from the findings of earlier research that suggest positive stock-bond correlation to be associated with periods of stagflation, i.e. when inflation is countercyclical (Burkhardt and Hasseltoft, 2012; Campbell et al., 2016; Song, 2016). However, during the sovereign crisis, high risk European countries, whose government bonds exhibited positive equity betas, were characterised by a procyclical inflation scenario with low growth and low inflation.

Our third contribution is an analysis of the portfolio allocation implications of our findings. The decoupling of the European sovereign bond market between high risk and low risk countries implies that sovereign bonds cannot be regarded as a homogenous asset class. As high risk sovereign bonds behave more like equities they no longer represent a hedge against stock market risk, no longer receive flight-to-safety funds, and their use for diversification purposes is profoundly altered. When looking at risk adjusted returns we reach the conclusion that indiscriminate diversification does not pay. It is best to diversify across low risk countries, with bond investments, equity investments or a mixture of the two. The upshot is that "prudent diversification" is a winning strategy both during crises and through the business cycle. Specifically, we observe that bonds from low risk countries appear to outperform all other portfolios considered across the crisis periods. This is due to particularly good risk adjusted returns during the subprime (2007-2009) and the first phase of the sovereign crisis (2010-2011) as they benefited from a flight-to-safety. However, low risk stocks appear to be the best through-the-cycle investment in risk adjusted terms. Given these findings, it is not surprising that a "pension fund" strategy, which diversifies across low risk stocks and low risk bonds, generates good Sharpe ratios both over the crisis periods and through the cycle.

are also positively correlated with stocks in that period but to a lower degree (.37 and .34 respectively). Reilly et al. (2009) show that, after the start of the new millennium, US investment grade corporate bonds become negatively related to the stock market. On the other hand, high yield corporate bonds remain positively related with the stock market throughout the sample period (1986-2009), an indication that these securities have consistently shown an "equity component" (Fridson, 1994).

${ }^{2}$ We thank the referee for making this point. 
Our fourth contribution is to show how the importance of credit and liquidity determinants varies across Euro-zone countries and between calm and crisis periods. We observe that market liquidity risk becomes statistically significant during the subprime and sovereign crisis periods. This is consistent with Beber et al. (2009) who conclude that credit risk usually accounts for the largest part of sovereign bond spreads but liquidity risk gains importance in times of market uncertainty. However, we find that liquidity risk does not affect countries indiscriminately, but only those that run into financial difficulties or are likely to be unable to service their debt. This establishes a plausible connection between liquidity and the level of credit risk faced by a sovereign (Pelizzon et al., 2016). We also show that credit risk does not appear to be priced before the subprime crisis but is important during the sovereign crisis. Interestingly, the influence of credit risk on bond returns drastically varies across countries. In low risk countries, the credit risk factor is positively related with bond returns. But, this relationship is negative and highly statistically significant in high risk countries. Hence, the empirical evidence strongly supports a flight-to-safety from high risk countries to low risk countries when sovereign default risk increases.

In this paper we focus on observable risk factors of sovereign bond yield changes. A related strand of the literature has also investigated unobservable factors. Geyer et al. (2004) and Favero et al. (2010) find that EMU sovereign yield spreads are largely driven by an unobservable time-varying common factor. Riedel et al. (2013) show that sovereign yield spreads also depend on an unobservable endogenous sovereign credit cycle. More recently, Kinateder and Wagner (2016) estimate time-varying unobservable common shocks on EMU government bond yield changes while allowing for heterogeneous country effects.

The rest of the paper is organised as follows. Variables description and model specification are presented in Section 2. Section 3 provides details of our data. In Sections 4 and 5 we discuss our results and robustness tests. Section 6 concludes the paper. 


\section{The model}

To study the determinants of European government bond returns and their time varying behaviour we estimate the following panel regression model over four distinct time periods: pre-crisis, subprime crisis and the acute and recovery phases of the sovereign crisis:

$$
\begin{aligned}
& \mathrm{RB}_{\mathrm{i}, \mathrm{cr}, \mathrm{t}}-\mathrm{RECB}_{\mathrm{t}} \\
& \qquad=\mathrm{c}+\omega_{\mathrm{i}}+\beta_{\mathrm{EQT}}\left(\mathrm{EQT}_{\mathrm{cr}, \mathrm{t}}-\mathrm{RECB}_{\mathrm{t}}\right)+\beta_{\mathrm{CDS}} \Delta \mathrm{CDS}_{\mathrm{cr}, \mathrm{t}}+\beta_{\mathrm{SPR}} \Delta \mathrm{Spr}_{\mathrm{i}, \mathrm{cr}, \mathrm{t}}+\epsilon_{\mathrm{i}, \mathrm{cr}, \mathrm{t}}
\end{aligned}
$$

where $R B_{i, c r, t}$ denotes the mid-price return for bond $i$ issued by country $c r$ on day $t, R E C B_{t}$ represents the 3 month ECB yield, $E Q T_{c r, t}$ is the country specific stock index return, $\triangle C D S_{c r, t}$ is the change in country specific 5 year CDS spreads, $\Delta S p r_{i, c r, t}$ is the change in bond specific bid-ask spread, $\omega_{\mathrm{i}}$ are bond fixed effects, and $c$ is the constant. We use a (within) panel estimator and panel robust standard errors. Following Cameron and Trivedi (2005) fixed effects are captured by demeaning the dependent and explanatory variables at the bond level. ${ }^{3}$ To ensure that no extreme movements bias our results, all return and change variables employed throughout our analysis are winsorized at $1 \%-99 \%$ considering all observations available, country by country, in each sub-period. All panel regressions are estimated with daily data.

The above model is in the spirit of Fama and French (1993) with the addition of the bidask spread variable to control for liquidity effects. ${ }^{4}$ However, differently from the original Fama and French model we do not explicitly consider a TERM factor. TERM is a proxy for maturity effects, or unexpected changes in interest rates, and is usually defined as the difference between a long-term government bond return and a short-term rate. The reason for its exclusion is that TERM is dominated by its first component, the long-term government bond return, which makes it undistinguishable from the dependent variable for bonds with long maturities. This severely impairs our ability to make any meaningful statistical inference regarding our main explanatory variables. ${ }^{5}$ Moreover, maturity effects tend to correlate with credit (and, to some extent, liquidity) effects which are already captured by our explanatory

\footnotetext{
${ }^{3}$ See Cameron and Trivedi (2005) pp. 697-706.

${ }^{4}$ Other studies also use liquidity measures in the CAPM framework. For instance, Li et al. (2009) implement a similar approach when analysing the effect of market-wide liquidity in the US treasury market.

${ }^{5}$ See Section 5.4 for a more detailed discussion regarding the TERM factor.
} 
variables. In the robustness Section we also control for maturity effects by interacting the equity factor with maturity dummies and by employing duration adjusted bond excess returns. Our main findings remain unaltered.

As a credit risk proxy we use the changes in 5 year CDS prices. Unlike credit ratings, which may be "sticky", CDS contracts are traded daily and represent the creditworthiness of an entity as viewed by the market rather than a rating agency. One problem when using CDS spreads is that these instruments may not be an accurate measure of default risk. Blanco et al. (2005) offer evidence that CDS spreads are considerably larger than credit bond spreads for US and European investment grade bonds. In more recent work, Bongaerts et al. (2011) find significant and robust evidence of a liquidity factor in corporate CDSs. Tang and Yan (2008), Chen et al. (2013), and Corò et al. (2013) reach similar conclusions for the corporate CDS market. Although we are aware of this issue, we assume that the liquidity bias is smallest for the 5 year CDS contract, as it is the most traded maturity (Gyntelberg et al., 2013).

The liquidity variable $\Delta S p r$ represents changes in bond specific proportional bid-ask spreads. Darbha and Dufour (2015) implement a horserace between several liquidity proxies on Eurozone sovereign bond markets and conclude that the proportional bid-ask spread is the most effective in capturing the variation of bond yields. Although our analysis examines bond returns instead of yields, we also expect the bid-ask spread to provide the best representation of illiquidity throughout our sample.

\section{Data}

In this study, we use a comprehensive database of tick-by-tick tradable prices for European government bonds provided by the MTS intra-dealer platform of the London Stock Exchange. MTS comprises bond information from 18 local cash markets and the European Benchmark Market, or EuroMTS, where only Euro benchmark bonds are traded. ${ }^{6}$ Euro benchmark bonds must have an outstanding value of at least $€ 5$ billion (Dufour and Skinner, 2004) and their quotes can be submitted simultaneously to both the local cash platform and EuroMTS. With an average daily turnover of more than $€ 100$ billion as of mid-2014, MTS

\footnotetext{
${ }^{6}$ As of May 2014, available Euro denominated bond cash markets include Austria, Belgium, Finland, France, Germany, Greece, Ireland, Italy, Netherlands, Portugal, and Spain. The other seven cash markets are Czech Republic, Denmark, Hungary, Israel, Poland, Slovenia, and United Kingdom.
} 
provides the best data source for the analysis of European government bonds. ${ }^{7}$ More information regarding the market microstructure of the MTS platforms is presented in Cheung et al. (2005) and Dunne et al. (2006) whereas the price discovery mechanisms are discussed in Dufour and Nguyen (2011) and Caporale and Girardi (2013). ${ }^{8}$ Beber et al. (2009) use the MTS data to construct bond liquidity and order flow measures.

Starting in April 2003, MTS Time Series offers high frequency historical bond data that contain the best three bid and ask prices together with their corresponding tradable sizes, and complete information regarding executed trades. Quote updates have time stamps with millisecond precision and, starting in 2013 , with microsecond precision. We consider only the information for the best bid and ask prices throughout the analysis. Our sample covers a period of more than 10 years, from April 2003 to December 2013, and includes 562 government bonds that belong to 11 Euro-zone countries: Austria, Belgium, Finland, France, Germany, Greece, Italy, Ireland, Netherlands, Portugal and Spain. All selected bonds are fixedcoupon benchmark bonds, have a maximum time to maturity of 51 years and trade on both the local cash market and EuroMTS. ${ }^{9}$

As is the case with any high frequency dataset, some steps are required to clean the data before they can be used in the analysis:

i. We select only quotes and trades recorded when the market is open, between 8:15 AM and 5:30 PM Central European Time (CET).

ii. Quote information from both the local market and EuroMTS is consolidated to form a new order book. We then use the consolidated order book to obtain the bond mid-price available at 5:00 PM CET each day. ${ }^{10}$

iii. All quote updates that have a bid price higher than or equal to the ask price are eliminated.

\footnotetext{
${ }^{7}$ For a comparison between MTS and other electronic platforms on European government bonds see Dunne et al. (2006), Persaud (2006) and ECB (2004, 2007).

${ }^{8}$ Also see Albanesi and Rindi (2000) for the evolution and market microstructure of MTS Italy, the institutional design model for EuroMTS and all other MTS cash markets.

${ }^{9}$ It is worth mentioning that bonds become benchmark bonds when the issue size criterion is met. As a result, a bond need not be a benchmark bond when issued, but can gain the benchmark status at a later date. This happens because some bonds are sold on the primary market in several tranches or tap sales. It is at the time when the bond receives the benchmark status that the bond starts trading on EuroMTS. We include in our analysis only the time period after the bond has received the Euro benchmark flag.

${ }^{10}$ Note that from the end of 2011 quotes for Greek bonds are no longer available on the MTS platform. Also, from 1st Jan 2010, we use the Composite Bloomberg Bond Trader (CBBT) mid-prices for Portuguese bonds because the firm bid and ask quotes posted on MTS are extremely wide making the mid-point prices very volatile.
} 
iv. We also address the issue of extremely high intraday bid-ask spreads by using a bond specific filter. The filter is applied each year and excludes the top $1 \%$ bid-ask spreads for each bond. This filter removes extreme and untradeable quote revisions without hindering the informational content of the order book.

We build our daily liquidity proxy for each bond as the average of all intra-day proportional bid-ask spreads weighted by the length of time each spread is displayed in the order book. For our credit risk factor we use daily 5 year CDS prices from Bloomberg. The CDS data is sourced from Credit Market Analysis (CMA) as the average of New York and London daily close prices. ${ }^{11}$ To illustrate how our liquidity and credit variables behave through time, Figure II shows the daily 5 year CDS spreads and average proportional bid-ask spreads for the 11 countries considered. Key crisis events are marked by spikes in our daily aggregate measures of credit and liquidity in each country. For the equity factor we employ daily stock index data from Datastream. Finally, our proxy for the risk-free rate is the 3 month ECB AAA yield. The ECB reports this measure daily starting from $6^{\text {th }}$ September 2004 . To obtain constant maturity yields, the ECB uses a Svensson (1994) fitting procedure on Euro-zone benchmark bond data of countries rated AAA by Fitch.

\section{Results}

Table I presents the mean and standard deviation for daily bond and stock returns by country. Countries are listed in a way that easily enables us to form groups that share common return characteristics on a consistent basis, as we will show in the rest of the analysis. Finland, Germany and the Netherlands are at the top of the list and we label them as "low risk". Austria, Belgium and France, are "medium risk" sovereigns. Greece, Ireland, Italy, Portugal and Spain are "high risk" countries.

We have identified four main sub-periods in our sample. The first is the pre-crisis, before August 2007, which is characterised by economic expansion and low market volatilities in

\footnotetext{
${ }^{11}$ Bloomberg reports CMA CDS prices starting 01 Oct 2004 for Austria, Belgium, Italy, Spain, Portugal and Greece. For the other 5 Euro-zone countries in our analysis, the starting date of the CDS data varies: 25 Jan 2005 for Germany, 29 Sep 2005 for the Netherlands, 25 Apr 2005 for Finland, 17 Aug 2005 for France, and 09 Jan 2008 for Ireland. Similar to Beber et al. (2009), a complete dataset of CDS prices are obtained using linear interpolation. Note that when we eliminate all interpolated data our results remain qualitatively unchanged.
} 
most of the countries in our sample. The level of interest rates in the Euro-zone increases in this period. As a result, average bond returns are negative for all the 11 countries under analysis. However, stock returns are generally positive over the same period.

In August 2007, PNB Paribas closed down three of their hedge funds highly specialized in US mortgage debt. This is one of the early events that signal major problems in the subprime market. Sovereign bond return averages become positive, with the exception of Greece, and may be indicative of a "flight-to-safety" as stock returns turn negative across Europe. We choose January 2010 as the start of the sovereign crisis in Europe. This is the time when investors learn that Greece might struggle to repay its debt. We split this period into two parts, each sub-period with a length of two years (from January 2010 to December 2011 and from January 2012 to December 2013), where we observe rather distinct bond and stock price movements. ${ }^{12}$

As shown in Figure I, in the first part of the sovereign debt crisis the bond market in the high risk countries become positively correlated with their stock markets. Investors now may perceive government securities from high risk sovereigns to be similar to stocks, that is, as if they were risky assets. On the contrary, the correlation between stocks and bonds in low risk countries remains negative in the first part of the sovereign crisis. This is also reflected in Table I where low risk bonds have positive mean returns during this sub-period. By contrast, high risk bonds have negative mean returns similar to most stock markets. The only exceptions are the equity markets in Finland and Ireland which are mildly positive, though both exhibit much higher volatility relative to pre-crisis levels.

In the second part of the sovereign debt crisis we observe reversals that may indicate the start of a recovery phase. Indeed, bond returns in low risk countries go back to pre-crisis (negative) levels. On the other hand, returns for all stock markets, and bond markets in high risk economies, become positive. Likely, higher confidence that a recovery is underway encourages investors to move away from low yielding safe assets and towards more risky ones, which represents a "flight-to-yield". Government bond returns for Greece in this subperiod are not reported due to the scarcity of reliable data. In this phase of the crisis, most Greek bonds were traded a few hours per day or not at all.

\footnotetext{
${ }^{12}$ As a robustness test we change the cut-off point between the acute and recovery phases of the sovereign crisis from 1st January 2012 to 1st July 2012. This is roughly the time when credit default swap spreads start to fall (see Figure II). The results remain qualitatively the same.
} 
We further explore the relationship between bond returns on one end and stock returns as well as credit and liquidity variables on the other, with univariate regressions, before employing the full regression model in Equation (1). Figure III presents the results when the equity, credit and liquidity factors are employed separately as the only explanatory variable. The signs of the equity betas confirm the findings previously described in Figure I. As expected, there is virtually no indication that either credit or liquidity factors influence sovereign bond prices in the pre-crisis period.

During the subprime crisis, CDS price changes in low risk countries are positively and statistically significantly related to bond returns. This suggests that higher credit risk in the local sovereign bond market does not deter investors from buying such securities. The likely implication is that as risk increases in all markets, those that are perceived to be less risky become winners, which is a classic flight-to-safety scenario. Indeed, for countries that later experienced solvency problems higher credit risk is associated with negative bond returns as investors shift to safer assets. The distinction between high and low risk countries becomes clear in the first part of the sovereign debt crisis when high risk countries exhibit a negative and statistically significant CDS coefficient which persists into the second part of the crisis.

With respect to liquidity effects, the coefficients of bid-ask spread changes are statistically significant only for high risk countries and with a negative sign. This phenomenon is similar to the one documented by Dick-Nielsen et al. (2012) in the US corporate bond market during the subprime crisis. They find that AAA corporate bonds are not affected by liquidity risk whereas lower-grade corporates are. This result is viewed as indicative of a flight from low to high grade corporates in times of crisis. This explanation would fit with the negative sovereign bond return of high risk countries and positive return of low risk countries in the first phase of the sovereign crisis (see Table I). In contrast, during the subprime crisis, we find a negative and significant liquidity coefficient for most of the high risk countries even though bond returns are mostly positive. This suggests a repositioning of investors from the stock market (where returns are mostly negative) into both high and low risk government bonds. Moreover, the repositioning in high risk countries would be, more specifically, towards liquid bonds. This is because the negative liquidity beta of high risk sovereigns indicates that only bonds with a contraction in bid-ask spreads would benefit from a positive return.

Next, we combine equity, credit and liquidity factors in our multivariate regression analysis. Results are reported in Table II. The findings are broadly in line with our preliminary 
intuitions based on the univariate analysis. However, the stock market coefficient for high risk countries is statistically significant and negative during the first part of the sovereign debt crisis period, contrary to what observed in the univariate case. This counter-intuitive result can be explained by the high negative correlation between the credit risk factor and the stock market in a crisis, which causes the latter to flip sign. As done in previous studies (e.g. Fama and French, 1993; Petkova 2006) we control for the interference generated by highly correlated variables through orthogonalization. Specifically, we replace the credit risk factor with its innovations, that is, the residuals obtained by regressing the factor against all the other explanatory variables in Equation (1). The results of the new model are reported in Table III and are now fully consistent with our prior expectations. We confirm a strong flightto-safety episode during the first part of the sovereign bond crisis when Euro zone investors move funds away from both stocks and bonds of high risk countries towards government bonds of low risk countries.

\subsection{Time-varying equity beta}

Table III clearly highlights that the equity beta of government bond returns is time varying. However, our results so far are silent about the factors behind such time variation. Therefore, we test a time series regression model over the whole sample period where the equity beta is allowed to vary over time. Its time variation is generated by the interaction between the equity factor and a selection of explanatory variables. These include macroeconomic fundamentals and financial variables we draw from the literature (details are shown in Appendix A) or, as an alternative, a country risk threshold indicator. We have computed daily changes of monthly/quarterly macro-variables by equally distributing the change in the relevant variable across all the trading days in the month/quarter. The model is estimated separately for each country and is specified as follows,

$$
R B_{t}-R E C B_{t}=c+\theta_{0}\left(E Q T_{t}-R E C B_{t}\right)+\sum_{j} \delta_{j} X_{j, t}\left(E Q T_{t}-R E C B_{t}\right)+\varepsilon_{t}
$$

where $R B_{t}$ is the average daily return across all benchmark bonds available for a specific country at time $\mathrm{t}$ and $X_{j, t}$ are the interacted factors. As a country risk indicator we use a dummy variable that takes the value 1 when the 5 year sovereign CDS of a country exceeds a 
pre-defined threshold, and zero otherwise. As a result, the time varying equity beta can be expressed as,

$$
\beta_{\mathrm{EQT}, \mathrm{t}}=\theta_{0}+\sum_{j} \delta_{j} X_{j, t}
$$

Figure IV shows, at the top, the pattern of the realised CAPM beta of the sovereign bonds of high risk versus low risk countries estimated with rolling 1 year time windows. As one should expect, these reflect the patterns of stock-bond correlations observed in Figure I, with a clear sign switch from negative to positive for high risk countries. In Figure IV we also present the plot of the time varying equity beta obtained by interacting the equity factor with our country risk dummy alone. The dummy enables our simple specification to capture the equity beta sign switch at the time it occurs, i.e. around the beginning of the sovereign crisis. The optimal credit spread threshold used to define the dummy is $2 \%$ which achieves the maximum explanatory power of our regression model across high risk countries. ${ }^{13}$ The identification of a threshold for country risk that can determine a sign switch in the equity beta has profound implications. First, it could be used as an important tripwire for fiscal policy makers. Exceeding the threshold will entail higher debt servicing costs and it will indicate a time when government bonds may no longer be treated by investors as a hedge against stock market risk. This alone may cause bond yields to go even higher producing a vicious circle with potentially serious repercussions for the sustainability of public debt and important consequences for public spending and taxation. Second, monetary policy could also be influenced by the threshold. The ECB intervened vigorously with unconventional measures to prevent or counter excessive government bond yields during the sovereign crisis. Our threshold could be used, alongside other indicators, to inform and guide central banks' decisions on when bond buying programmes are needed to pre-empt large sell offs of government debt from investors. Third, the country risk threshold could also be embedded in systemic risk and stress testing models, now widely used by macro prudential regulators, as a crisis indicator.

\footnotetext{
${ }^{13}$ We have tried different thresholds 25 basis points apart from $1 \%$ to $3 \%$ and found $2 \%$ to be the best one.
} 
Next, we test whether macro-variables as well as changes in sovereign CDS spreads and bond bid-ask spreads can explain the sign change in equity beta. As show in Figure IV we find that, like the country risk dummy, they do capture the change in sign. However, with the country risk dummy the sign switch of the conditional equity beta occurs at the same time as for the realised beta, i.e. at the beginning of the sovereign crisis. But, when using macro and other financial factors the sign switch is anticipated to the middle of the sub-prime crisis, more than a year earlier, which is not consistent with observed data. The conditional equity betas in Figure IV are estimated with alternative specifications of Equation (2) where the excess return of the equity factor is interacted with the country risk dummy alone (second graph of Figure IV) or with all the macro factors with the exclusion of the country risk dummy (third graph). The regression results of these alternative models are reported in Table IV (Model II and IV respectively) together with other specifications. By adding sequentially macro factors (results unreported) we found that the determining macro variable to explain the sign switch in equity beta, though with imperfect timing, appears to be the 5 year correlation between economic growth (proxied with industrial production) and inflation. However, we observed that growth-inflation correlation alone could not achieve this outcome but only through a complex interaction with other macro factors. Also, while in the literature (Burkhardt and Hasseltoft, 2012; Campbell et al., 2016; Song, 2016) such correlation is negatively related to the equity beta, we find that its sign and significance vary widely across countries (Models III to V). Indeed, if we look at its sign when used with all other macro and financial variables (Model IV) it is positive and highly statistically significant for Netherlands, Austria, Belgium and Spain, negative and highly significant for Germany, Finland, Italy, Portugal and Greece and not significant for France and Ireland. So, the observation in the literature that stock bond covariance (or equity beta) is positive when inflation and economic growth are inversely related (e.g. in stagflation periods) and negative when inflation and growth are positively related (e.g. during the subprime and sovereign crisis when both were low) does not appear to have general validity. Indeed, when inspecting such relationship graphically we could not find obvious patterns. When adding to the macro factors the country risk dummy (Model V) the growth-inflation correlation turns consistently negative but only for high risk countries. 


\subsection{Implications for portfolio allocation}

Our regression results reveal a clear decoupling between high and low risk bond returns starting from the beginning of the sovereign crisis. The contrasting sign of the returns between the two types of sovereign debt and their different relationship with key risk factors suggest a radical shift in investors' behaviour. Here, we explore how such phenomenon may affect investors with different risk appetite and asset allocation strategies. Specifically, we look at how the crises have altered diversification opportunities across stocks and bonds. To address these points we first group stocks and bonds according to the risk profile of the country of issue. We call "low risk" assets those issued in low risk countries, namely Germany, Finland and Netherlands, while "high risk" assets are issued in Italy, Spain, Portugal, Ireland or Greece. Table V presents the descriptive statistics and correlations between the asset classes in each time period. As one would expect, correlations between the high risk and low risk stocks is high throughout the sample period with its peak during the subprime crisis at $91 \%$.

More importantly, while correlation between the high and low risk bond portfolios is high in the pre-crisis and subprime periods (99.5\% and $87.9 \%$ respectively), it drops dramatically and even turns negative during the two phases of the sovereign crisis $(-19.6 \%$ and $-17.6 \%$ respectively). This is strong evidence of the deep decoupling in the European sovereign bond market between high and low risk countries. The two types of government securities are clearly perceived and traded as if they were different asset classes: one as a safe asset to invest into in a crisis, the other, more like stocks, as a higher yield asset to invest into in recovery periods. Indeed, the correlations between high risk bonds and stocks become substantially positive during the sovereign crisis, while it was markedly negative in previous periods.

Clearly, this sharp change in correlation has major implications for fund managers and how they can diversify risk. To explore this point we build five equally weighted asset portfolios that differ by asset composition (diversified as opposed to concentrated) and risk profile (low or high risk). The portfolios are (1) a pure bond fund with equally weighted bond indices of low and high risk countries, (2) a pure equity fund with equally weighted equity indices of low and high risk countries, (3) a diversified fund that includes all the above, (4) a pension fund, with low risk stocks and bonds and (5) a hedge fund with positions in high risk stocks and bonds. Next, we look at the risk adjusted returns of each portfolio, before and 
during the crisis periods, with modified Sharpe ratios. It is well known that the Sharpe ratio is uninformative when returns are negative, since higher volatility will increase the ratio (i.e. it would make it less negative) thus reversing its usual interpretation. The solution proposed by Israelsen (2005) addresses this problem. ${ }^{14}$ Our main findings, reported in Table VI, are as follows.

First, unsurprisingly, if an investor had perfect foresight they would prefer "pure" portfolio strategies, i.e. portfolios that are made of a specific asset class (stocks or bonds) and risk profile (high or low) rather than more diversified portfolios. It is interesting that during the subprime and sovereign crisis periods bond portfolios exhibit the largest Sharpe ratios. Portfolios of sovereign bonds from low risk countries outperform all other pure and diversified strategies in the subprime crisis and the first part of the sovereign crisis with a modified Sharpe ratio of 0.06 and 0.67 respectively. This is likely the result of a flight-to-safety from other asset classes (including high risk sovereign bonds). In the second part of the sovereign crisis, which is characterised by a marked recovery, sovereign bonds from high risk countries make the largest risk adjusted gains (1.72) and dominate all other strategies. This is confirmed by panel $\mathrm{D}$ in Table $\mathrm{V}$ where we see a mean return of high risk bonds at $13.2 \%$ which, although lower than that of stocks, is also much less volatile.

As we extend the holding period we observe that often pure strategies still dominate. Low risk bonds exhibit the highest Sharpe ratio $(0.17)$ over the whole crisis period including the subprime and sovereign crises. However, low risk stocks appear to be the preferred option when we extend the holding period to the pre-crisis $(0.27)$. Both strategies are characterised by relatively low diversification (i.e. investment restricted to a specific asset class) and low risk. The upshot is that indiscriminate diversification across asset classes is never a winning strategy in the observation period. Instead, "prudent diversification", i.e. restricted to low risk assets, yields the best outcomes in risk adjusted terms for buy-and-hold investors. Diversifying across asset classes with low risk, the typical approach of a pension fund for example, also exhibits consistently good results over longer horizons. This is because low risk

\footnotetext{
${ }^{14}$ Israelsen (2005) reformulates the Sharpe measure as the product (rather than the ratio) of excess returns and volatility when excess returns are negative. This implies that the modified Sharpe measure can provide a meaningful ranking of portfolio performances. However, the difference between the modified Sharpe measures of two portfolios that exhibit excess return of opposite sign cannot be used to quantify the extent to which one portfolio is better than the other in risk adjusted terms.
} 
government bonds have persistently negative equity beta, which implies that they produce substantial diversification gains when combined with stocks.

\section{Robustness}

\subsection{Quantitative Easing}

During the subprime and sovereign crises, the European Central Bank took extensive unconventional monetary policy measures aimed at easing financial conditions. To explore the impact of such measures on sovereign bond returns and stock-bond covariances we have built dummy variables to capture the above effects in line with previous literature (Alter and Beyer, 2014; Beirne et al., 2011; Fawley and Neely, 2013; Fratzscher et al., 2014; Krishnamurthy et al., 2014; Szczerbowicz, 2015). We include 4 dummies in our Equation (1) which control for the following ECB actions: (1) ECB announcements of unconventional policy measures obtained from ECB press releases; (2) allotment days of long-term refinancing operations (LTRO) with maturity of 6 months or higher sourced from the ECB history of all open market operations; ${ }^{15}$ (3) days when securities market programs (SMP) are active obtained from weekly ECB financial statements; and (4) days when covered bond purchase programmes (CBPP) are active sourced from the ECB statistical data warehouse. We also account for changes in broad money supply via conventional ECB policies by including in the regression the Euro Area monetary aggregate M3 (available from the ECB statistical data warehouse). The monthly change in $\mathrm{M} 3$ is distributed equally across all trading days in the month. As can be seen in Table VII, our results are robust to the inclusion of ECB unconventional and conventional policy dummies. The incremental change in R-squared is very small and neither the significance nor the sign of the main coefficients change. We also try several alternative model specifications: (a) We include distinct ECB unconventional policy dummies for each announcement and intervention date; (b) We replace the SMP and CBPP dummy variables with the log of actual ECB purchases under the two programs; and (c) We

\footnotetext{
${ }^{15}$ In response to the deteriorating liquidity conditions experienced by Eurozone banks because of the crisis, the ECB decided to (i) extend the maturity of the LTRO above the conventional 3 months and to (ii) offer unlimited capital for the same interest rate (fixed-rate full allotment procedure). Thus, the LTRO allotment date marks an exceptional demand of capital.
} 
consider changes in Euro area total assets instead of the Euro area monetary aggregate M3. All these tests do not change qualitatively any of our findings. ${ }^{16}$

\subsection{Flights-to-Safety}

Abnormally large negative correlations may influence, and possibly drive, the sign of our equity betas. We have extended our analysis to control for events when stocks and bonds exhibit significantly large returns in the opposite direction. Following Baele et al. (2015) and Ermolov (2015) we introduce a flight-to-safety dummy that captures instances when bond returns are abnormally positive and stock returns are abnormally negative within a specific country. "Abnormal" returns are those that deviate from their mean by more than 2 standard deviations. Results are reported in Table VIII. Even when controlling for flights-to-safety all our main conclusions remain unaltered. Interestingly, the equity beta of Greece becomes positive and highly statistically significant during the sub-prime crisis. This suggests that by controlling for extreme events when bonds attract flying stock investors, Greek sovereign bonds begin to acquire "equity-like" features even before the sovereign debt crisis.

\subsection{International Risk Factor and LOIS Spread}

Codogno et al. (2003) and Favero et al. (2010) employ an international risk factor in their analysis of European sovereign bond returns. Constructed as the spread between the 10 year US interest swap rate and the 10 year Treasury bond rate, this factor is typically viewed as a global measure of investors' risk aversion. Aït-Sahalia et al. (2012) and Schwarz (2016) use the LOIS spread given by the difference between the 3 month EURIBOR and EONIA rates, which should capture credit and liquidity shocks in the interbank money market. We add changes of these two variables to our model in Equation (1) and present the results in Table IX. The international risk factor is highly statistically significant and negative in the pre-crisis and subprime crisis periods for all countries included in our analysis. However, the effect of this factor disappears altogether in the sovereign debt crisis period. This is suggestive of investors shifting their attention away from the US markets and focusing more on European risk factors. The LOIS spread is highly statistically significant and positive for all countries during all time periods except for high risk countries where it dies out with the start of the sovereign debt

\footnotetext{
${ }^{16}$ These results are available on request.
} 
crisis. Overall, the combined effect of both factors is substantial during the pre-crisis period (i.e. a $6 \%$ increase in the $\mathrm{R}$-squared on average), but becomes negligible as the financial crisis intensifies. Our results are robust to the introduction of these additional factors.

\subsection{The TERM Factor}

Fama and French (1993) include a TERM factor as a determinant of government bond returns to capture maturity effects. This is commonly defined as the difference between a long-term government bond return and a short-term government bond rate. We build the TERM factor as the return difference between a 10 year bond portfolio specific to each country and the 3 month ECB rate. ${ }^{17,18}$ This factor appears to be an appropriate explanatory variable for stocks and corporate bonds. However, we note that our TERM factor is completely dominated by the long-term bond component as the variability and magnitude of the 3 month ECB rate are both relatively much smaller. Table $X$ presents the country specific correlation between the TERM factor and excess bond returns for short, medium and longterm maturity bands. Most countries exhibit very high correlation values especially for medium and long-term bonds. To illustrate the negligible impact of the short-term government rate in TERM we also report the correlation between the excess bond return and TERM defined simply as the 10 year bond return (that is, without subtracting the short-term return). Correlations remain virtually unchanged. When using TERM in our regressions (unreported results) several variables exhibit counter-intuitive signs and/or statistical significance.

Therefore, instead of employing TERM, we control for maturity effects in two alternative ways. First, we interact the equity factor with maturity dummies. As shown in Table XI our results are confirmed and the equity like behaviour of high risk bonds during the sovereign crisis appears to be pervasive across maturities. Second, following Chen et al. (2007) we also run our main regression on bond returns standardised by duration (unreported). Our findings remain virtually the same. None of the coefficients changes in sign or significance and Rsquared's only increase slightly as compared to the ones in the original Table III. We interpret this result as further evidence that our results are robust to maturity effects.

\footnotetext{
${ }^{17}$ To build the time series of the 10 year bond portfolio we average, each day, all country specific bond returns with a remaining time-to-maturity between 9 and 11 years.

${ }^{18}$ We also consider the 3 month EURIBOR rate instead of the 3 month ECB rate. Results remain unchanged.
} 


\subsection{Liquidity Proxies}

Besides the bid-ask spread we have looked at other proxies to capture liquidity effects in the sovereign bond market. The illiquidity proxy suggested by Schwarz (2016) is a Euro-zone market-wide (i.e. systematic) illiquidity measure defined as the yield difference between $\mathrm{KfW}$ bonds (fully backed by the German government) and Bunds. We have downloaded from Bloomberg the daily yield series for $79 \mathrm{KfW}$ bonds from 2003 to 2010. This is the total number of KfW bonds that have more than 2 million EUR outstanding over the period. For consistency, we also rely on Bloomberg to obtain yield information for the German sovereign bonds in our sample. We then follow Schwarz (2016)'s methodology and build the liquidity measure for 3 maturity bands: $1.5-2.5$ years, $4.5-5.5$ years, and $9.5-10.5$ years.

The 10 year KFW illiquidity measure presents several discontinuities over the time period because of a lack of $\mathrm{KfW}$ bonds with a remaining time to maturity of $9.5-10.5$ years. Therefore, we rely on daily changes in the 5 year series. Regression results with the Schwarz measure are shown in Table XII. Our main findings remain qualitatively unchanged except for occasional higher or lower significance for the CDS and bid-ask spread variables (for low and medium risk countries). Surprisingly, during the sub-prime crisis the coefficient of this illiquidity proxy is positive and statistically significant for all countries which appears to suggest that it may capture illiquidity trends outside the government bond market. The implication is that the severe liquidity shortages observed during the sub-prime crisis across a number of asset classes have benefited government bonds regardless of country risk, the likely result of a flight-to-safety. The same effect remains during the sovereign debt crisis but only for low and medium risk countries, as one would expect (though for medium risk countries the effect is only significant in the first part of the sovereign crisis). On the other hand, high risk countries exhibit a negative and highly statistically significant coefficient which again conforms to our expectation of investors moving away from government securities when issuing countries experience distress.

We have also considered depth as an alternative bond-specific liquidity proxy. For each intra-day quote update, depth is defined as the average tradable size available at the best bid and the best ask. Daily observations are computed as an average of all intra-day depth 
observations weighted by the time each quote update was available in the order book. This variable proved not to be statistically significant in most regressions.

\subsection{Predicting Country Risk}

The distinction we make between high, medium and low risk countries is based on ex post observation. Peripheral countries were clearly more affected by the sovereign crisis than other Euro members. One may wonder whether an investor could draw different lessons from our portfolio performance analysis if they could predict which countries would suffer the most in a crisis. With this in mind we looked at government bond yields to see if they could enable one to predict the decoupling observed during the sovereign crisis. Figure $V$ shows the 1 year moving averages of the dummies that capture above median sovereign yields for each country at each point in time. It appears that when Lehman's default occurred (denoted by the black vertical line) all low risk countries (Germany, Netherlands and Finland) had sovereign bond yields below the median of the 11 sample countries, and the high risk countries (Italy, Ireland, Spain, Portugal and Greece) had yields above the median. This is interesting and relevant because, at that point in time, an investor who is looking for an exit will need to decide which safe assets to invest into. With inference made at that point in time we can see that the split that appears between high risk and low risk countries is almost identical to that in our original analysis. The only difference is that Belgium would be categorised as a high (rather than medium) risk country. We have re-estimated our main panel regression with the new groupings. Our (unreported) results remain qualitatively unchanged. Also our conclusions on risk adjusted performance do not change. ${ }^{19}$

\subsection{Other Robustness Tests}

We perform several other robustness tests. First, we change the cut-off date used to split the sovereign debt crisis in two intervals from 01 January 2012 to 01 July 2012 as there is a clear reduction in both CDS prices and bond bid-ask spreads after this date. Besides some loss in coefficient significance for the medium risk countries, the remaining results are virtually the same. Second, in the main analysis we use clean price returns. We test whether accrued

\footnotetext{
${ }^{19}$ Results are available from the authors on request.
} 
interest has an impact on our results by estimating the dirty price for each bond. We use the following formula to compute bond returns:

$$
R B_{i, t}=\frac{\left(P_{i, t}+A I_{i, t}+C_{i, t}\right)}{\left(P_{i, t-1}+A I_{i, t-1}\right)}-1
$$

where $R B_{i, t}$ represents the bond return of bond $i$ on day $t, P_{i, t}$ is the clean price, $A I_{i, t}$ is the accrued interest at time $\mathrm{t}$ and $C_{i, t}$ represents any coupon received in the period $t-1$ to $t$. Using dirty price return does not change our conclusions. Finally, to examine the sensitivity of our findings to our credit risk proxy, we replace our CDS data sourced from CMA with 5 year CDS prices, denominated in US dollars, for our 11 Euro-zone countries with Bloomberg's generic pricing source CBGN. We obtain very similar results with our original ones. Furthermore, we also consider 10 year CDS prices sourced from CMA and repeat our analysis. Again our findings remain unchanged.

\section{Conclusion}

The crises of the last decade offer a unique opportunity to study how the return of government bonds and stocks co-move when the market is subject to stress conditions of different degree and type. Using a comprehensive dataset of European sovereign bond prices stretching over a period of 10 years we find that government bonds of high risk countries lost their "safe-asset" status during the recent sovereign debt crisis. They have exhibited more equity-like behaviour since then, with positive and strongly significant co-movements relative to the stock market as well as abnormally high levels of volatility. We observe that the sign switch in stock-bond covariance from negative to positive is primarily associated with high levels of sovereign default risk. We identify a credit spread of $2 \%$ as the critical default risk threshold that is best related to flipping stock-bond covariances. Changes in macro-economic fundamentals are less successful in explaining such changes in co-variation. Further, we observe that the crisis-induced decoupling in the government bond market between high risk and low risk countries appears to generate superior risk adjusted returns for investors that engage in "prudent diversification" by focusing on low risk bonds and/or low risk stocks. We 
also find that indiscriminate diversification yields sub-optimal performance, in risk adjusted terms, both in crisis periods and through-the-cycle.

Both credit and liquidity risks are important factors in explaining the variation of sovereign bond returns. But they behave differently depending on the perceived creditworthiness of the country. If the country has a low probability of default, then credit impacts positively bond returns. For high risk countries the impact is negative. Both these results suggest a flight-tosafety. The other main risk factor, liquidity risk, seems to affect only distressed countries.

One of the aspects that we have not explored in this study is the impact on sovereign bond returns of an implicit public guarantee that Euro membership may offer. Useful insights on this point may be drawn from the studies that look at the pricing implications on agency bonds of the implicit support enjoyed by Government Sponsored Enterprises in the US (e.g. Frame and White, 2005 and 2007; Passmore, 2005; Hancock and Passmore, 2010). Our analysis clearly shows that any implicit guarantee from Euro membership, even if present, was not sufficient to prevent the stark decoupling in the sovereign bond market between high risk and low risk countries that we have documented. Although this could have distorted the pricing of sovereign debt and contained credit and liquidity effects, it is likely that our main conclusions would have been stronger if such distortion had been accounted for. How much stronger they would have been, and the likely systemic risk repercussions if such guarantee became less credible, are interesting topics for future research. 


\section{References}

Acharya, V., Drechsler, I., \& Schnabl, P. (2014) “A pyrrhic victory? Bank bailouts and sovereign credit risk" Journal of Finance, 69(6), 2689-2739.

Aït-Sahalia, Y., Andritzky, J., Jobst, A., Nowak, S., and Tamirisa, N., (2012) "Market response to policy initiatives during the global financial crisis" Journal of International Economics (87), 162-177.

Albanesi, S., and Rindi, B., (2000) "The Quality of the Italian Treasury Bond Market, Asymmetric Information and Transaction Costs" Annales D'economie Et De Statistique (60), 1-19.

Almeida, H., Cunha, I., Ferreira, M. A. and Restrepo, F. (2016) "The Real Effects of Credit Ratings: The Sovereign Ceiling Channel" Journal of Finance, Forthcoming.

Alter, A., and Beyer, A., (2014) "The dynamics of spillover effects during the European sovereign debt turmoil" Journal of Banking \& Finance 42, 134-153.

Baele, L., Bekaert, G., Inghelbrecht, K., and Wei, M., (2015) "Flights to Safety" National Bank of Belgium Working Paper No. 230.

Beber, A., Brandt, M. W., and Kavajecz, K. A., (2009) "Flight-to-Quality or Flight-to-Liquidity? Evidence from the Euro-Area Bond Market" Review of Financial Studies 22 (3), 925-957.

Beirne, J., Dalitz, L., Ejsing, J., Grothe, M., Manganelli, S., Monar, F., Sahel, B., Susec, M., Tapking, J., and Vong, T., (2011) "The Impact of the Eurosystem's Covered Bond Purchase Programme on the Primary and Secondary Markets" ECB Occasional Paper No. 122.

Blanco, R., Brennan, S., and Marsh, I. W., (2005) "An Empirical Analysis of the Dynamic Relationship between Investment Grade Bonds and Credit Default Swaps" Journal of Finance 60(5), 2255-2281.

Blume, M. E., Keim, D. B., and Patel, S. A., (1991) "Returns and Volatility of Low-Grade Bonds 1977-1989" Journal of Finance, 46(1), 49-74.

Bongaerts, D., de Jong, F., and Driessen, J., (2011) "Derivative Pricing with Liquidity Risk: Theory and Evidence from the Credit Default Swap Market" Journal of Finance 66(1), 203-240.

Burkhardt, D., and Hasseltoft, H., (2012) "Understanding asset correlations" Swiss Finance Institute Research Paper No. 12-38.

Cameron, A.C., Trivedi, P.K., (2005) "Microeconometrics: Methods and Applications" Cambridge University Press.

Campbell, J. Y., Sunderam, A., and Viceira, L. M., (2016) "Inflation bets or deflation hedges? The changing risks of nominal bonds" Critical Finance Review, Forthcoming. 
Campbell, J.Y., Pflueger, C., and Viceira, L.M., (2015) "Monetary Policy Drivers of Bond and Equity Risks" Harvard Business School Working Paper 14-031.

Caporale, G. M., and Girardi, A., (2013) "Price discovery and trade fragmentation in a multimarket environment: Evidence from the MTS system" Journal of Banking \& Finance 37(2), 227-240.

Chen, L., Lesmond, D.A., and Wei, J., (2007) "Corporate Yield Spreads and Bond Liquidity" Journal of Finance 62(1), 119-149.

Chen, R., Cheng, X., and Wu, L., (2013) "Dynamic Interactions between Interest-Rate and Credit Risk: Theory and Evidence on the Credit Default Swap Term Structure" Review of Finance 17(1), 403-441.

Cheung, Y., de Jong, F., and Rindi, B., (2005) "Trading European sovereign bonds - The microstructure of the MTS trading platforms" ECB Working Paper No. 432.

Codogno, L., Favero, C., Missale, A., Portes, R., and Thum, M., (2003) "Government bond spreads" Economic Policy 18(37), 503-532.

Connolly, R., Stivers, C., and Sun, L., (2005) "Stock Market Uncertainty and the Stock-Bond Return Relation" Journal of Financial and Quantitative Analysis 40(1), 161-194.

Corò, F., Dufour, A., and Varotto, S., (2013) “Credit and liquidity components of corporate CDS spreads" Journal of Banking \& Finance 37(12), 5511-5525.

Darbha, M. and Dufour, A., (2015) “Euro area government bond market liquidity" Working Paper.

David, A., and Veronesi, P., (2013) "What ties return volatilities to price valuations and fundamentals?" Journal of Political Economy 121, 682-746.

Dick-Nielsen, J., Feldhütter, P., and Lando, D., (2012) "Corporate bond liquidity before and after the onset of the subprime crisis" Journal of Financial Economics 103(3), 471-492.

Dufour, A. and Skinner, F., (2004) "MTS Time Series: Market and Data Description for the European Bond and Repo Database" Working Paper.

Dufour, A., and Nguyen, M., (2012) "Permanent Trading Impacts and Bond Yields" European Journal of Finance, 18(9), 841-864.

Dunne, P. G., Moore, M., and Portes, R., (2006) "European Government Bond Markets: Transparency, Liquidity, Efficiency" CEPR, London, UK.

Ermolov, A., (2015) "Time-varying Risk of Nominal Bonds: How Important Are Macroeconomic Shocks?" Columbia Business School Working Paper. 
Eser, F. and Schwaab, B., (2016) "Evaluating the impact of unconventional monetary policy measures: Empirical evidence from the ECB's Securities Markets Programme" Journal of Financial Economics 119, 147-167.

European Central Bank (2004) "The euro bond market study" https://www.ecb.europa.eu/pub/pdf/other/eurobondmarketstudy2004en.pdf .

European Central Bank (2007) "The euro bonds and derivatives markets" http://www.ecb.europa.eu/pub/pdf/other/eurobondmarketstudy200706en.pdf .

Fama, E.F., and French, K.R., (1993) "Common risk factors in the returns on stocks and bonds" Journal of Financial Economics 33(1), 3-56.

Favero, C., Pagano, M., and von Thadden, E.-L., (2010) "How Does Liquidity Affect Government Bond Yields?" Journal of Financial and Quantitative Analysis 45(1), 107-134.

Fawley, B.W., and Neely, C.J., (2013) "Four stories of quantitative easing" Federal Reserve Bank of St. Louis Review January/February, 51-88.

Frame, W. S., and White, L. J., (2005) "Fussing and Fuming over Fannie and Freddie: How Much Smoke, How Much Fire?” Journal of Economic Perspectives 19(2), 159-184.

Frame, W. S., and White, L. J., (2007) "Charter Value, Risk-Taking Incentives, and Emerging Competition for Fannie Mae and Freddie Mac" Journal of Money, Credit and Banking 39(1), 83-103.

Fratzscher, M., Duca, M.L., and Straub, R., (2014) “ECB Unconventional Monetary Policy Actions: Market Impact, International Spillovers and Transmission Channels" IMF $15^{\text {th }}$ Jacques Polak Annual Research Conference: "Cross-Border Spillovers".

Fridson, M. S., (1994) “Do High-Yield Bonds Have an Equity Component?" Financial Management 23(2), 82-84.

Gapen, M., Gray, D., Lim, C.H., Xiao, Y., (2008) “Measuring and Analyzing Sovereign Risk with Contingent Claims" IMF Staff Papers 55(1), 109-148.

Geyer, A., Kossmeier, S. and S. Pichler (2004) "Measuring systematic risk in EMU government yield spreads" Review of Finance 8, 171-197.

Gyntelberg, J., Hördahl, P., Ters, K., Urban, J., (2013) "Intraday Dynamics of Euro Area Sovereign CDS and Bonds" BIS Working Paper No. 423.

Gray, D., Merton, R., Bodie, Z., (2007) Contingent Claims Approach to Measuring and Managing Sovereign Credit Risk. Journal of Investment Management 5, 1-24. 
Hancock, D., and Passmore, S.W., (2010) "An Analysis of Government Guarantees and the Functioning of Asset-Backed Securities Markets" FEDS Working Paper No. 2010-46.

Hau, H., and Lai, S., (2016) "Asset allocation and monetary policy: Evidence from the Eurozone" Journal of Financial Economics 120, 309-329.

Israelsen, C., (2005) "A refinement to the Sharpe ratio and information ratio" Journal of Asset Management 5, 423-427.

Kinateder, H., Wagner, N., (2016) "Quantitative Easing and the Pricing of EMU Sovereign Debt" Working Paper.

Krishnamurthy, A., Nagel, S., and Vissing-Jorgensen, A., (2015) "ECB Policies involving Government Bond Purchases: Impact and Channels" Haas Business School Working Paper.

Li, H., Wang, J., Wu, C., and He, Y., (2009) "Are Liquidity and Information Risks Priced in the Treasury Bond Market?" Journal of Finance 64(1), 467-503.

Longstaff, F. A., Pan, J., Pedersen, L. H. and Singleton, K. J., (2011) "How sovereign is sovereign credit risk?" American Economic Journal: Macroeconomics 3(2), 75-103.

Passmore, S.W., (2005) "The GSE Implicit Subsidy and the Value of Government Ambiguity" Real Estate Economics 33(3), 465-486.

Pelizzon, L., Subrahmanyam, M. G., Tomio, D., and Uno, J., (2016) "Sovereign credit risk, liquidity, and ECB intervention: Deus ex machina?" Journal of Financial Economics 122(1), 86-115.

Persaud, A. D., (2006) "Improving efficiency in the European government bond market" ICAP Publications.

Petkova, R., (2006) "Do the Fama-French Factors Proxy for Innovations in Predictive Variables" Journal of Finance 61(2), 581-612.

Reilly, F.K., Wright, D.J., and Gentry, J.A., (2009) "Historic Changes in the High Yield Bond Market" Journal of Applied Corporate Finance 21(3), 65-79.

Riedel, C., Thuraisamy, Wagner, N., (2013) "Credit Cycle Dependent Spread Determinants in Emerging Sovereign Debt Markets" Emerging Markets Review 17, 209-223.

Schwarz, K., (2016) "Mind the Gap: Disentangling Credit and Liquidity in Risk Spreads" Wharton School Working Paper.

Song, D., (2016) "Bond Market Exposures to Macroeconomic and Monetary Policy Risks" Boston College Working Paper 915. 
Svensson, L. E., (1994) "Estimating and Interpreting Forward Interest Rates: Sweden 19921994" CEPR Discussion Paper No. 1051.

Szczerbowicz, U., (2015) "The ECB Unconventional Monetary Policies: Have They Lowered Market Borrowing Costs for Banks and Governments?" International Journal of Central Banking 11(4), 91-127.

Tang, D., and Yan, H., (2008) "Liquidity and credit default swap spreads" Working Paper.

Weigel, D. D., and Gemmill, G., (2006) "What drives credit risk in emerging markets? The roles of country fundamentals and market co-movements" Journal of International Money and Finance 25(3), 476-502.

White, H. (1980) "A heteroskedasticity-consistent covariance matrix estimator and a direct test for heteroskedasticity" Econometrica 48(4), 817-838. 
Table I

\section{Summary Statistics for Sovereign Bond Returns and Equity Returns}

The table shows the annualized averages and standard deviations of daily sovereign bond and equity returns for each country in our sample in percentage points. The pre-crisis covers the time period from 01 Oct 2004 until 31 Jul 2007. The subprime crisis period denotes the time period between 01 Aug 2007 and 31 Dec 2009. The first part of the sovereign debt crisis goes from 01 Jan 2010 to 30 Dec 2011 and the second part between 01 Jan 2012 to 31 Dec 2013. The following representative stock market indices are used for each country in our sample: DAX (30 stocks, Germany), AEX (25 stocks, Netherlands), OMXHelsinki (25 stocks, Finland), CAC(40 stocks, France), ATX(20 stocks, Austria), BEL(20 stocks, Belgium), MIB(40 stocks, Italy), IBEX(35 stocks, Spain), PSI(20 stocks, Portugal), ISEQ(20 stocks, Ireland), ATHEX(20 stocks, Greece).We employ simple returns following Fama and French (1993).

Panel A: Sovereign Bond Returns (\%)

\begin{tabular}{|c|c|c|c|c|c|c|c|c|}
\hline & \multicolumn{2}{|c|}{ Pre-crisis period } & \multicolumn{2}{|c|}{ Subprime crisis period } & \multicolumn{2}{|c|}{ Sovereign crisis period I } & \multicolumn{2}{|c|}{ Sovereign crisis period II } \\
\hline & Mean & St.Dev. & Mean & St.Dev. & Mean & St.Dev. & Mean & St.Dev. \\
\hline Germany & -0.7 & 3.4 & 2.6 & 6.1 & 3.8 & 6.3 & -1.5 & 5.4 \\
\hline Netherlands & -0.9 & 4.0 & 3.0 & 6.2 & 4.0 & 6.7 & -1.1 & 5.5 \\
\hline Finland & -1.1 & 2.8 & 2.6 & 4.2 & 1.4 & 4.4 & -1.7 & 4.9 \\
\hline France & -0.8 & 4.0 & 3.2 & 6.2 & 1.4 & 7.1 & 0.2 & 5.5 \\
\hline Austria & -1.4 & 3.8 & 2.3 & 6.6 & 2.6 & 6.6 & 0.1 & 6.6 \\
\hline Belgium & -0.9 & 4.2 & 2.9 & 5.9 & -0.3 & 7.5 & 3.5 & 5.3 \\
\hline Italy & -1.0 & 3.5 & 2.5 & 5.1 & -6.0 & 9.4 & 7.1 & 8.1 \\
\hline Spain & -0.9 & 3.9 & 2.0 & 6.4 & -2.0 & 10.3 & 4.0 & 10.3 \\
\hline Portugal & -1.4 & 3.4 & 2.4 & 6.1 & -21.4 & 17.3 & 22.2 & 17.6 \\
\hline Ireland & -0.3 & 3.8 & 1.3 & 6.4 & -5.3 & 18.0 & 18.1 & 41.3 \\
\hline Greece & -1.3 & 3.5 & -1.0 & 7.2 & -26.1 & 30.4 & NA & NA \\
\hline
\end{tabular}

Panel B: Equity Index Returns (\%)

\begin{tabular}{|c|c|c|c|c|c|c|c|c|}
\hline & \multicolumn{2}{|c|}{ Pre-crisis period } & \multicolumn{2}{|c|}{ Subprime crisis period } & \multicolumn{2}{|c|}{ Sovereign crisis period I } & \multicolumn{2}{|c|}{ Sovereign crisis period II } \\
\hline & Mean & St.Dev. & Mean & St.Dev. & Mean & St.Dev. & Mean & St.Dev. \\
\hline Germany & 24.0 & 16.8 & -8.0 & 30.5 & -0.7 & 23.8 & 21.1 & 16.6 \\
\hline Netherlands & 18.1 & 15.4 & -12.9 & 33.1 & -1.1 & 21.2 & 13.1 & 14.2 \\
\hline Finland & 24.4 & 14.4 & -12.5 & 32.6 & 1.2 & 26.0 & 20.0 & 19.5 \\
\hline France & 18.4 & 14.5 & -10.0 & 31.8 & -7.2 & 25.9 & 16.4 & 18.2 \\
\hline Austria & 32.0 & 15.5 & -17.3 & 38.9 & -9.9 & 26.2 & 16.0 & 18.7 \\
\hline Belgium & 22.6 & 12.4 & -17.8 & 29.2 & -6.5 & 22.2 & 17.4 & 15.4 \\
\hline Italy & 14.5 & 12.2 & -16.6 & 31.8 & -16.4 & 29.3 & 13.9 & 24.4 \\
\hline Spain & 21.3 & 13.1 & -3.8 & 30.7 & -11.9 & 28.7 & 9.8 & 23.5 \\
\hline Portugal & 21.0 & 9.5 & -15.1 & 25.0 & -18.1 & 23.0 & 10.2 & 18.4 \\
\hline Ireland & 17.3 & 14.1 & -33.2 & 40.7 & 2.7 & 22.6 & 22.8 & 14.6 \\
\hline Greece & 30.6 & 17.3 & -26.4 & 37.5 & -60.6 & 42.1 & 26.5 & 41.5 \\
\hline
\end{tabular}


Table II

Determinants of Excess Sovereign Bond Returns by Country Group

This table reports panel regression coefficients for the following model:

$R B_{i, c r, t}-R E C B_{t}=c+\beta_{E Q T}\left(E Q T_{c r, t}-R E C B_{t}\right)+\beta_{C D S} \Delta C D S_{c r, t}+\beta_{S P R} \Delta S p r_{i, c r, t}+\varepsilon_{i, c r, t}$

where $\mathrm{RB}_{\mathrm{i}, \mathrm{cr}, \mathrm{t}}$ denotes the mid-price return for bond $\mathrm{i}$ issued by country cr on day $\mathrm{t}, \mathrm{RECB}_{\mathrm{t}}$ represents the 3 month ECB yield, $\mathrm{EQT}_{\text {cr,t }}$ is the country specific stock index return, $\triangle \mathrm{CDS}$ cr,t is the change in country specific 5 year CDS spreads, $\Delta \mathrm{Spr}_{\mathrm{i}, \mathrm{r}, \mathrm{t}}$ is the change in bond specific proportional bid-ask spread. We employ daily observations. For each sub-period, regressions variables are winsorized at $1 \%$ and $99 \%$ taking into account all time-series observations demeaned at the bond level. Sub-periods are from 01 Oct 2004 to 31 Jul 2007 for the pre-crisis, from 01 Aug 2007 to 31 Dec 2009 for the subprime crisis; the sovereign crisis is split into two parts, from 01 Jan 2010 to 30 Dec 2011 and between 01 Jan 2012 and 31 Dec 2013 . White (1980) cross-section standard errors and covariances are used. $* * *, * *$, and $*$ represent statistical significance at the $1 \%, 5 \%$, and $10 \%$ level, respectively.

\begin{tabular}{|c|c|c|c|c|c|c|c|c|}
\hline & \multicolumn{4}{|c|}{ Panel A: Low Risk Countries (Germany, Netherlands and Finland) } & \multicolumn{4}{|c|}{ Panel B: Medium Risk Countries (France, Austria and Belgium) } \\
\hline Coefficient & $\begin{array}{l}\text { Pre-crisis } \\
\text { period }\end{array}$ & $\begin{array}{c}\text { Subprime crisis } \\
\text { period }\end{array}$ & $\begin{array}{c}\text { Sovereign crisis } \\
\text { period I }\end{array}$ & $\begin{array}{c}\text { Sovereign crisis } \\
\text { period II }\end{array}$ & $\begin{array}{l}\text { Pre-crisis } \\
\text { period }\end{array}$ & $\begin{array}{c}\text { Subprime crisis } \\
\text { period }\end{array}$ & $\begin{array}{c}\text { Sovereign crisis } \\
\text { period I }\end{array}$ & $\begin{array}{c}\text { Sovereign crisis } \\
\text { period II }\end{array}$ \\
\hline$\beta_{E Q T}$ & $-0.024 * * *$ & $-0.059 * * *$ & $-0.087 * * *$ & $-0.057 * * *$ & $-0.033 * * *$ & $-0.060 * * *$ & $-0.097 * * *$ & $-0.017 *$ \\
\hline$\beta_{C D S}$ & -0.283 & 0.893 & $1.483 * * *$ & $1.511 * * *$ & $-2.389 *$ & -0.381 & $-1.913 * * *$ & $-1.649 * * *$ \\
\hline$\beta_{S P R}$ & -0.616 & -0.235 & -0.265 & -0.079 & -0.685 & -0.130 & $-0.170 *$ & 0.022 \\
\hline $\operatorname{Adj}-R^{2}$ & $1.29 \%$ & $12.13 \%$ & $19.09 \%$ & $6.14 \%$ & $1.91 \%$ & $10.29 \%$ & $9.78 \%$ & $3.57 \%$ \\
\hline Per/Cross-sec & $643 / 73$ & $609 / 84$ & $513 / 98$ & $507 / 111$ & $722 / 68$ & $609 / 75$ & $513 / 86$ & $507 / 108$ \\
\hline \multirow[t]{2}{*}{$\# O b s$} & 30,455 & 35,932 & 36,737 & 43,689 & 33,323 & 37,427 & 36,464 & 42,724 \\
\hline & \multicolumn{4}{|c|}{ Panel C: High Risk Countries (Italy, Ireland, Spain and Portugal) } & \multicolumn{4}{|c|}{ Panel D: Greece } \\
\hline Coefficient & $\begin{array}{l}\text { Pre-crisis } \\
\text { period }\end{array}$ & $\begin{array}{c}\text { Subprime crisis } \\
\text { period }\end{array}$ & $\begin{array}{c}\text { Sovereign crisis } \\
\text { period I }\end{array}$ & $\begin{array}{l}\text { Sovereign crisis } \\
\text { period II }\end{array}$ & $\begin{array}{l}\text { Pre-crisis } \\
\text { period }\end{array}$ & $\begin{array}{c}\text { Subprime crisis } \\
\text { period }\end{array}$ & $\begin{array}{c}\text { Sovereign crisis } \\
\text { period I }\end{array}$ & $\begin{array}{l}\text { Sovereign crisis } \\
\text { period II }\end{array}$ \\
\hline$\beta_{E Q T}$ & $-0.024 * * *$ & $-0.045 * * *$ & $-0.019 *$ & $0.052 * * *$ & $-0.018 * * *$ & $-0.018 * * *$ & $0.046 * *$ & NA \\
\hline$\beta_{C D S}$ & -0.454 & $-0.875 * * *$ & $-2.161 * * *$ & $-2.517 * * *$ & 0.669 & $-1.970 * * *$ & $-2.419 * * *$ & NA \\
\hline$\beta_{S P R}$ & -1.422 & $-0.375 * * *$ & $-0.089 * * *$ & 0.003 & -0.643 & $-0.082 * *$ & -0.038 & NA \\
\hline$A d j-R^{2}$ & $0.82 \%$ & $6.15 \%$ & $27.06 \%$ & $36.90 \%$ & $1.01 \%$ & $6.55 \%$ & $30.90 \%$ & NA \\
\hline Per/Cross-sec & $722 / 81$ & $609 / 105$ & $513 / 119$ & $507 / 140$ & $722 / 26$ & $609 / 26$ & $390 / 24$ & $N A$ \\
\hline \#Obs & 41,646 & 45,175 & 50,419 & 54,385 & 13,721 & 12,359 & 5,007 & $N A$ \\
\hline
\end{tabular}




\section{Table III}

\section{Determinants of Excess Sovereign Bond Returns with Orthogonalized Credit Factor}

This table reports panel regression coefficients for the following model:

$$
R B_{i, c r, t}-R E C B_{t}=c+\beta_{E Q T}\left(E Q T_{c r, t}-R E C B_{t}\right)+\beta_{C D S O} \Delta C D S O_{c r, t}+\beta_{S P R} \Delta S p r_{i, c r, t}+\varepsilon_{i, c r, t}
$$

where $\mathrm{RB}_{\mathrm{i}, \mathrm{cr}, \mathrm{t}}$ denotes the mid-price return for bond $\mathrm{i}$ issued by country cr on day $\mathrm{t}, \mathrm{RECB}_{\mathrm{t}}$ represents the 3 month ECB yield, EQT $\mathrm{E}_{\text {cr, }}$ is the country specific stock index return, $\Delta \mathrm{CDSO} \mathrm{C}_{\text {cr, }}$ is the change in country specific 5 year CDS spreads orthogonalized with respect to the other regressors, $\Delta \mathrm{Spr}_{\mathrm{i}, \mathrm{cr}, \mathrm{t}}$ is the change in bond specific proportional bid-ask spread. We employ daily observations. For each sub-period, regressions variables are winsorized at $1 \%$ and $99 \%$ taking into account all time-series observations demeaned at the bond level. Sub-periods are from 01 Oct 2004 to 31 Jul 2007 for the pre-crisis, from 01 Aug 2007 to 31 Dec 2009 for the subprime crisis; the sovereign crisis is split into two parts, from 01 Jan 2010 to 30 Dec 2011 and between 01 Jan 2012 and 31 Dec 2013 . White (1980) cross-section standard errors and covariances are used. $* * *, * *$, and * represent statistical significance at the $1 \%, 5 \%$, and $10 \%$ level, respectively.

Panel A: Low Risk Countries (Germany, Netherlands and Finland)

Panel B: Medium Risk Countries (France, Austria and Belgium)

\begin{tabular}{|c|c|c|c|c|c|c|c|c|}
\hline Coefficient & $\begin{array}{l}\text { Pre-crisis } \\
\text { period }\end{array}$ & $\begin{array}{c}\text { Subprime crisis } \\
\text { period }\end{array}$ & $\begin{array}{c}\text { Sovereign crisis } \\
\text { period I }\end{array}$ & $\begin{array}{c}\text { Sovereign crisis } \\
\text { period II }\end{array}$ & $\begin{array}{l}\text { Pre-crisis } \\
\text { period }\end{array}$ & $\begin{array}{c}\text { Subprime crisis } \\
\text { period }\end{array}$ & $\begin{array}{c}\text { Sovereign crisis } \\
\text { period I }\end{array}$ & $\begin{array}{c}\text { Sovereign crisis } \\
\text { period II }\end{array}$ \\
\hline$\beta_{E Q T}$ & $-0.024 * * *$ & $-0.061 * * *$ & $-0.101 * * *$ & $-0.068 * * *$ & $-0.033 * * *$ & $-0.059 * * *$ & $-0.052 * * *$ & 0.010 \\
\hline$\beta_{C D S O}$ & -0.283 & 0.893 & $1.483 * * *$ & $1.511 * * *$ & $-2.389 *$ & -0.381 & $-1.913 * * *$ & $-1.649 * * *$ \\
\hline$\beta_{S P R}$ & -0.623 & -0.228 & -0.255 & -0.046 & -0.704 & -0.138 & $-0.226 * *$ & -0.026 \\
\hline $\operatorname{Adj-} R^{2}$ & $1.29 \%$ & $12.13 \%$ & $19.09 \%$ & $6.14 \%$ & $1.91 \%$ & $10.29 \%$ & $9.78 \%$ & $3.57 \%$ \\
\hline Per/Cross-sec & $643 / 73$ & $609 / 84$ & $513 / 98$ & $507 / 111$ & $722 / 68$ & $609 / 75$ & $513 / 86$ & $507 / 108$ \\
\hline \multirow[t]{2}{*}{ \#Obs } & 30,455 & 35,932 & 36,737 & 43,689 & 33,323 & 37,427 & 36,464 & 42,724 \\
\hline & \multicolumn{4}{|c|}{ Panel C: High Risk Countries (Italy, Ireland, Spain and Portugal) } & \multicolumn{4}{|c|}{ Panel D: Greece } \\
\hline Coefficient & $\begin{array}{l}\text { Pre-crisis } \\
\text { period }\end{array}$ & $\begin{array}{c}\text { Subprime crisis } \\
\text { period }\end{array}$ & $\begin{array}{l}\text { Sovereign crisis } \\
\text { period I }\end{array}$ & $\begin{array}{l}\text { Sovereign crisis } \\
\text { period II }\end{array}$ & $\begin{array}{l}\text { Pre-crisis } \\
\text { period }\end{array}$ & $\begin{array}{c}\text { Subprime crisis } \\
\text { period }\end{array}$ & $\begin{array}{l}\text { Sovereign crisis } \\
\text { period I }\end{array}$ & $\begin{array}{c}\text { Sovereign crisis } \\
\text { period II }\end{array}$ \\
\hline$\beta_{E Q T}$ & $-0.024 * * *$ & $-0.039 * * *$ & $0.096 * * *$ & $0.171 * * *$ & $-0.018 * * *$ & 0.000 & $0.184 * * *$ & NA \\
\hline$\beta_{C D S O}$ & -0.454 & $-0.875 * * *$ & $-2.161 * * *$ & $-2.517 * * *$ & 0.669 & $-1.970 * * *$ & $-2.419 * * *$ & NA \\
\hline$\beta_{S P R}$ & -1.442 & $-0.406 * * *$ & $-0.115 * * *$ & -0.009 & -0.642 & $-0.105 * *$ & $-0.076 * * *$ & NA \\
\hline $\operatorname{Adj-} R^{2}$ & $0.82 \%$ & $6.15 \%$ & $27.06 \%$ & $36.90 \%$ & $1.01 \%$ & $6.55 \%$ & $30.90 \%$ & NA \\
\hline Per/Cross-sec & $722 / 81$ & $609 / 105$ & $513 / 119$ & $507 / 140$ & $722 / 26$ & $609 / 26$ & $390 / 24$ & $N A$ \\
\hline$\# O b s$ & 41,646 & 45,175 & 50,419 & 54,385 & 13,721 & 12,359 & 5,007 & $N A$ \\
\hline
\end{tabular}


Table IV

Determinants of Excess Sovereign Bond Returns with Time-Varying Equity Beta

This table reports the results of the following time series regression model estimated separately for each country:

$$
R B_{t}-R E C B_{t}=c+\theta_{0}\left(E Q T_{t}-R E C B_{t}\right)+\sum_{j} \delta_{j} X_{j} *\left(E Q T_{t}-R E C B_{t}\right)+\varepsilon_{t}
$$

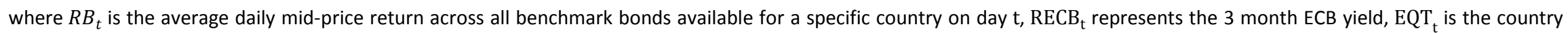
specific stock index return and $X_{j}$ represents the following macroeconomic and financial variables (details in Appendix A): a country risk dummy (SovRisk) which takes the value 1 when the country's 5 year sovereign CDS exceeds $2 \%$, output gap, changes in real GDP, changes in debt to GDP ratio, changes in retail sales, changes in unemployment, changes in consumer price index, changes in imports, changes in exports, changes in industrial production, changes in M3, changes in economic sentiment, changes in the orthogonalised credit default swap spread, $\Delta \mathrm{CDSO}_{\mathrm{t}}$, changes in average bid-ask spread across all benchmark bonds available for a specific country on day $\mathrm{t}$, $\Delta \mathrm{Spr}_{\mathrm{t}}$, and the rolling 5 -year correlation between industrial production growth and inflation, $\rho(\mathrm{IP}, \mathrm{Inf})_{\mathrm{t}}$. Models I to $\mathrm{V}$ represent alternative specifications of the equation above. Model I does not consider any interaction terms. In Models II and III excess equity returns are interacted only by the country risk dummy and the correlation between industrial production growth and inflation, respectively. In Model IV we use all macro and financial variables excluding the country risk dummy. Finally, Model V includes all the macro and financial variables. In Models IV and V, we only report the coefficients for the excess equity return factor and the interacted country risk dummy and the industrial production growth - inflation correlation. The Wald test is used to assess whether the coefficients of other interacted factors are jointly equal to 0 . We employ daily observations covering the period from 09 Sep 2004 to 31 Dec 2013 . Regressions variables are winsorized at 1\% and 99\% on the following sub-periods: 01 Oct 2004 to 31 Jul 2007 (pre-crisis), 01 Aug 2007 to 31 Dec 2009 (subprime crisis), 01 Jan 2010 to 30 Dec 2011 (sovereign debt crisis part I), and 01 Jan 2012 to 31 Dec 2013 (sovereign debt crisis part II). White (1980) cross-section standard errors and covariances are used.

\begin{tabular}{|c|c|c|c|c|c|c|c|c|c|}
\hline \multirow[b]{2}{*}{ Country } & \multicolumn{2}{|c|}{ Model I } & \multicolumn{3}{|c|}{ Model II } & \multicolumn{3}{|c|}{ Model III } & \multirow[b]{2}{*}{$\# O b$} \\
\hline & $\theta_{0}$ & $\operatorname{Adj}-R 2$ & $\delta_{\text {SovRisk }}$ & $\theta_{0}$ & Adj-R2 & $\delta_{\rho(\mathrm{IP}, \mathrm{Inf})}$ & $\theta_{0}$ & Adj-R2 & \\
\hline Germany & $-0.077 * * *$ & $18 \%$ & 0.000 & $-0.077 * * *$ & $18 \%$ & $-0.187 * * *$ & $-0.070 * * *$ & $19 \%$ & 2273 \\
\hline Netherlands & $-0.075 * * *$ & $16 \%$ & 0.000 & $-0.075 * * *$ & $16 \%$ & $0.340 * * *$ & $-0.089 * * *$ & $17 \%$ & 2095 \\
\hline Finland & $-0.056 * * *$ & $17 \%$ & 0.000 & $-0.056 * * *$ & $17 \%$ & $-0.085 * *$ & $-0.042 * * *$ & $17 \%$ & 2209 \\
\hline France & $-0.061 * * *$ & $11 \%$ & $0.110 * * *$ & $-0.066 * * *$ & $12 \%$ & -0.042 & $-0.058 * * *$ & $11 \%$ & 2129 \\
\hline Austria & $-0.041 * * *$ & $6 \%$ & 0.041 & $-0.043 * * *$ & $6 \%$ & $0.220 * * *$ & $-0.047 * * *$ & $7 \%$ & 2351 \\
\hline Belgium & $-0.031 * * *$ & $2 \%$ & $0.104 * * *$ & $-0.048 * * *$ & $5 \%$ & $0.434 * * *$ & $-0.040 * * *$ & $4 \%$ & 2351 \\
\hline Italy & $0.056 * * *$ & $6 \%$ & $0.180 * * *$ & $-0.016 * * *$ & $22 \%$ & $-0.898 * * *$ & $0.106 * * *$ & $11 \%$ & 2352 \\
\hline Spain & $0.044 * * *$ & $3 \%$ & $0.192 * * *$ & $-0.041 * * *$ & $18 \%$ & $0.670 * * *$ & -0.002 & $8 \%$ & 2352 \\
\hline Portugal & $0.064 * * *$ & $2 \%$ & $0.223 * * *$ & $-0.047 * * *$ & $8 \%$ & $-0.835 * * *$ & $0.142 * * *$ & $3 \%$ & 2351 \\
\hline Ireland & 0.007 & $0 \%$ & $0.067 * * *$ & $-0.019 * * *$ & $1 \%$ & 0.391 & $0.042 * *$ & $0 \%$ & 1520 \\
\hline Greece & $0.066 * * *$ & $4 \%$ & $0.175 * * *$ & $-0.012 * *$ & $12 \%$ & $-0.650 * * *$ & $0.153 * * *$ & $8 \%$ & 1715 \\
\hline
\end{tabular}


Table IV - Continued

\begin{tabular}{|c|c|c|c|c|c|c|c|c|c|c|}
\hline \multirow[b]{2}{*}{ Country } & \multicolumn{4}{|c|}{ Model IV } & \multicolumn{6}{|c|}{ Model V } \\
\hline & $\begin{array}{c}\text { Wald F-stat } \\
\forall \delta_{j}=0 \text { excl. } \\
\delta_{\rho(\text { IP,Inf })} \& \\
\delta_{\text {SovRisk }}\end{array}$ & $\delta_{\rho(\mathrm{IP}, \mathrm{Inf})}$ & $\theta_{0}$ & Adj-R2 & $\begin{array}{c}\text { Wald F-stat } \\
\forall \delta_{j}=0 \text { excl. } \\
\delta_{\rho(\text { IP,Inf })} \& \\
\delta_{\text {SovRisk }}\end{array}$ & $\delta_{\rho(\mathrm{IP}, \mathrm{Inf})}$ & $\delta_{\text {SovRisk }}$ & $\theta_{0}$ & $\operatorname{Adj-R2}$ & $\# O b s$ \\
\hline Germany & $2.798 * * *$ & $-0.336 * * *$ & $-0.062 * * *$ & $20 \%$ & $2.798^{* * *}$ & $-0.336 * * *$ & 0.000 & $-0.062 * * *$ & $20 \%$ & 2273 \\
\hline Netherlands & $2.445^{* * *}$ & $0.454 * * *$ & $-0.098 * * *$ & $18 \%$ & $2.445^{* * *}$ & $0.454 * * *$ & 0.000 & $-0.098 * * *$ & $18 \%$ & 2095 \\
\hline Finland & $2.700 * * *$ & $-0.112 * *$ & $-0.031 * * *$ & $18 \%$ & $2.700 * * *$ & $-0.112 * *$ & 0.000 & $-0.031 * * *$ & $18 \%$ & 2209 \\
\hline France & 1.438 & 0.051 & $-0.065 * * *$ & $11 \%$ & 1.373 & -0.014 & $0.118 * * *$ & $-0.064 * * *$ & $13 \%$ & 2129 \\
\hline Austria & $2.255^{* * *}$ & $0.236 * * *$ & $-0.050 * * *$ & $8 \%$ & $2.192 * * *$ & $0.227 * * *$ & 0.019 & $-0.051 * * *$ & $8 \%$ & 2351 \\
\hline Belgium & 1.512 & $0.573 * * *$ & $-0.041 * * *$ & $5 \%$ & 1.288 & $0.300 * * *$ & $0.084 * * *$ & $-0.046 * * *$ & $7 \%$ & 2351 \\
\hline Italy & $5.664 * * *$ & $-1.178 * * *$ & $0.105 * * *$ & $16 \%$ & $4.115^{* * *}$ & $-0.415 * * *$ & $0.169 * * *$ & 0.001 & $24 \%$ & 2352 \\
\hline Spain & $8.092^{* * *}$ & $0.261 * *$ & $0.072 * * *$ & $14 \%$ & $5.255^{* * *}$ & $-0.326 * * *$ & $0.183 * * *$ & -0.008 & $20 \%$ & 2352 \\
\hline Portugal & $5.511 * * *$ & $-1.446 * * *$ & $0.152 * * *$ & $8 \%$ & $4.220^{* * *}$ & $-0.545 * *$ & $0.206 * * *$ & -0.018 & $11 \%$ & 2351 \\
\hline Ireland & $2.078^{* *}$ & -0.462 & 0.031 & $2 \%$ & 1.512 & -0.467 & $0.036 *$ & 0.011 & $2 \%$ & 1520 \\
\hline Greece & $6.828 * * *$ & $-0.377 * *$ & $0.096 * * *$ & $20 \%$ & $3.411 * * *$ & $-0.253 *$ & $0.106 * * *$ & $0.052 * *$ & $20 \%$ & 1715 \\
\hline
\end{tabular}




\section{Table V}

Descriptive Statistics of Bond and Stock Portfolios

This table presents the mean, standard deviation and correlations between four asset portfolios. LR Stock and LR Bond denote low risk stock and bond portfolios that include the stock market indices and average sovereign bond returns, respectively, of Germany, Finland and Netherlands. HR_Stock and HR_Bond are high risk stock and bond portfolios that include the stock market indices and average sovereign bond returns, respectively, of Italy, Spain, Portugal, Ireland and Greece. The mean return and standard deviation measures have been annualised from daily estimates. Sub-periods are from 01 Oct 2004 to 31 Jul 2007 for the pre-crisis, from 01 Aug 2007 to 31 Dec 2009 for the subprime crisis; the sovereign crisis is split into two parts, from 01 Jan 2010 to 30 Dec 2011 and between 01 Jan 2012 and 31 Dec 2013.

\begin{tabular}{|c|c|c|c|c|c|c|c|c|c|c|c|}
\hline \multicolumn{6}{|c|}{ Panel A: Pre-crisis period } & \multicolumn{6}{|c|}{ Panel B: Subprime crisis period } \\
\hline & \multirow{2}{*}{$\begin{array}{l}\text { Mean } \\
\text { Return }\end{array}$} & \multirow{2}{*}{$\begin{array}{l}\text { Standard } \\
\text { Deviation }\end{array}$} & \multicolumn{3}{|c|}{ Correlations } & & \multirow{2}{*}{$\begin{array}{l}\text { Mean } \\
\text { Return }\end{array}$} & \multirow{2}{*}{$\begin{array}{l}\text { Standard } \\
\text { Deviation }\end{array}$} & \multicolumn{3}{|c|}{ Correlations } \\
\hline & & & LR_Stock & HR_Stock & LR_Bond & & & & LR_Stock & HR_Stock & LR_Bond \\
\hline LR_Stock & $21.2 \%$ & $12.6 \%$ & & & & LR_Stock & $-11.8 \%$ & $30.9 \%$ & & & \\
\hline HR_Stock & $19.7 \%$ & $10.2 \%$ & $88.3 \%$ & & & HR_Stock & $-19.8 \%$ & $29.3 \%$ & $91.0 \%$ & & \\
\hline LR_Bond & $-1.0 \%$ & $2.5 \%$ & $-14.9 \%$ & $-15.7 \%$ & & LR_Bond & $2.7 \%$ & $4.2 \%$ & $-45.7 \%$ & $-44.5 \%$ & \\
\hline \multirow[t]{4}{*}{ HR_Bond } & $-1.4 \%$ & $2.7 \%$ & $-14.2 \%$ & $-14.5 \%$ & $99.5 \%$ & HR_Bond & $1.4 \%$ & $4.4 \%$ & $-30.9 \%$ & $-28.4 \%$ & $87.9 \%$ \\
\hline & \multicolumn{4}{|c|}{ Panel C: Sovereign crisis period I } & & \multicolumn{6}{|c|}{ Panel D: Sovereign crisis period II } \\
\hline & Mean & Standard & \multicolumn{3}{|c|}{ Correlations } & & Mean & Standard & \multicolumn{3}{|c|}{ Correlations } \\
\hline & Return & Deviation & LR_Stock & HR_Stock & LR_Bond & & Return & Deviation & LR_Stock & HR_Stock & LR_Bond \\
\hline LR_Stock & $-0.2 \%$ & $23.1 \%$ & & & & LR_Stock & $18.7 \%$ & $16.1 \%$ & & & \\
\hline HR_Stock & $-21.5 \%$ & $24.9 \%$ & $86.6 \%$ & & & HR_Stock & $17.1 \%$ & $18.6 \%$ & $77.3 \%$ & & \\
\hline LR_Bond & $3.5 \%$ & $4.4 \%$ & $-61.0 \%$ & $-60.1 \%$ & & LR_Bond & $-1.0 \%$ & $3.7 \%$ & $-35.6 \%$ & $-33.5 \%$ & \\
\hline HR_Bond & $-12.3 \%$ & $11.2 \%$ & $27.6 \%$ & $45.0 \%$ & $-19.6 \%$ & HR_Bond & $13.2 \%$ & $7.7 \%$ & $40.0 \%$ & $42.1 \%$ & $-17.6 \%$ \\
\hline
\end{tabular}


Table VI

\section{Portfolio Performance}

This table presents the modified Sharpe ratio (Israelsen 2005) of various investment strategies. Group bond/stock portfolio returns are obtained as an average of bond/stock portfolio returns belonging to the countries inside the group. Country-specific bond portfolio returns are estimated as return averages of all sovereign benchmark bonds of a country. The low risk group includes Germany, the Netherlands, and Finland while the high risk group is formed by Italy, Spain, Portugal, Ireland, and Greece. Excess returns are estimated using the 3 month ECB yield as a proxy for the risk-free rate.We employ daily observations. The full sample period covers 09 Sep 2004 to 31 Dec 2013 (FULL). Sub-periods are from 01 Oct 2004 to 31 Jul 2007 for the pre-crisis (PRE), from 01 Aug 2007 to 31 Dec 2009 for the subprime crisis (SUB), from 01 Jan 2010 to 30 Dec 2011 and from 01 Jan 2012 to 31 Dec 2013 for the first (SOV I) and second (SOV II) part of the sovereign debt crisis, respectively.

\begin{tabular}{|c|c|c|c|c|c|c|c|}
\hline Portfolios & Pre & Sub & Sov 1 & Sov II & Sov I + II & Sub \& Sov I + II & Full \\
\hline Stock low risk (SL) & 1.46 & -0.04 & -0.00 & 1.15 & 0.44 & 0.01 & 0.27 \\
\hline Stock high risk (SH) & 1.66 & -0.07 & -0.05 & 0.92 & -0.01 & -0.02 & -0.00 \\
\hline Bond low risk (BL) & -0.00 & 0.06 & 0.67 & -0.00 & 0.23 & 0.17 & -0.00 \\
\hline Bond high risk $(\mathrm{BH})$ & -0.00 & -0.00 & -0.01 & 1.72 & 0.01 & -0.00 & -0.00 \\
\hline Diversified fund (All) & 1.26 & -0.01 & -0.01 & 1.34 & 0.17 & -0.00 & 0.05 \\
\hline High yield fund (SH\&BH) & 1.27 & -0.02 & -0.03 & 1.32 & -0.00 & -0.01 & -0.00 \\
\hline Pension fund (SL\&BL) & 1.18 & -0.01 & 0.11 & 1.15 & 0.54 & 0.04 & 0.25 \\
\hline Equity fund (SL\&SH) & 1.60 & -0.05 & -0.03 & 1.09 & 0.16 & -0.01 & 0.10 \\
\hline Bond fund (BL\&BH) & -0.00 & -0.00 & -0.00 & 1.53 & 0.11 & 0.04 & -0.00 \\
\hline
\end{tabular}




\section{Table VII}

\section{Determinants of Excess Sovereign Bond Returns: ECB's Quantitative Easing and Money Supply Effects}

This table reports panel regression coefficients for the following model:

$$
R B_{i, c r, t}-R E C B_{t}=c+\beta_{E Q T}\left(E Q T_{c r, t}-R E C B_{t}\right)+\beta_{C D S O} \Delta C D S O_{c r, t}+\beta_{S P R} \Delta S p r_{i, c r, t}+\beta_{E U R O M}{ }_{3} \Delta E U R O M 3_{t}+\beta_{A n n} \text { Announcement }+\beta_{L T R O} L T R O_{D U M}+\beta_{S M P} S M P_{D U M}
$$

$$
+\beta_{C B P P} C B P P_{D U M}+\varepsilon_{i, c r, t}
$$

where $\mathrm{RB}_{\mathrm{i}, \mathrm{cr}, \mathrm{t}}$ denotes the mid-price return for bond $\mathrm{i}$ issued by country cr on day $\mathrm{t}, \mathrm{RECB}_{\mathrm{t}}$ represents the 3 month $\mathrm{ECB}$ yield, $\mathrm{EQT}_{\mathrm{cr}, \mathrm{t}}$ is the country specific stock index return, $\Delta \mathrm{CDSO}_{\text {cr,t }}$ is the change in country specific 5 year CDS spreads orthogonalized with respect to the other continuous regressors, $\Delta$ Spr $_{i, c r, t}$ is the change in bond specific proportional bid-ask spread, Announcement is a dummy variable that takes a value of 1 on dates when the ECB announces unconventional policy measures, LTRO DuM is a dummy variable that takes a value of 1 on allotment dates for longterm refinancing operations with a maturity higher than 3 months, $\mathrm{SMP}_{\mathrm{DUM}}$ and $\mathrm{CBPP}_{\mathrm{DUM}}$ are dummy variables that take a value of 1 in the weeks (Securities Market Program) or days (Covered Bond Purchase Program) when securities were purchased by the ECB, $\triangle E U R O M 3_{t}$ is the percentage change in the Euro Area monetary aggregate M3 (daily series is obtained by assuming each monthly change is realised equally, divide by 20 , throughout the days of the month it covers). We employ daily observations. For each sub-period, regressions variables are winsorized at $1 \%$ and 99\% taking into account all time-series observations demeaned at the bond level. Sub-periods are from 01 Oct 2004 to 31 Jul 2007 for the pre-crisis, from 01 Aug 2007 to 31 Dec 2009 for the subprime crisis; the sovereign crisis is split into two parts, from 01 Jan 2010 to 30 Dec 2011 and between 01 Jan 2012 and 31 Dec 2013. White (1980) cross-section standard errors and covariances

\begin{tabular}{|c|c|c|c|c|c|c|c|c|}
\hline \multirow[b]{2}{*}{ Coefficient } & \multicolumn{4}{|c|}{ Panel A: Low Risk Countries (Germany, Netherlands and Finland) } & \multicolumn{4}{|c|}{ Panel B: Medium Risk Countries (France, Austria and Belgium) } \\
\hline & $\begin{array}{l}\text { Pre-crisis } \\
\text { period }\end{array}$ & $\begin{array}{l}\text { Subprime crisis } \\
\text { period }\end{array}$ & $\begin{array}{c}\text { Sovereign crisis } \\
\text { period I }\end{array}$ & $\begin{array}{l}\text { Sovereign crisis } \\
\text { period II }\end{array}$ & $\begin{array}{l}\text { Pre-crisis } \\
\text { period }\end{array}$ & $\begin{array}{c}\text { Subprime crisis } \\
\text { period }\end{array}$ & $\begin{array}{c}\text { Sovereign crisis } \\
\text { period I }\end{array}$ & $\begin{array}{c}\text { Sovereign crisis } \\
\text { period II }\end{array}$ \\
\hline$\beta_{E Q T}$ & $-0.020 * *$ & $-0.036 * * *$ & $-0.101 * * *$ & $-0.066 * * *$ & $-0.031 * * *$ & $-0.028 * * *$ & $-0.053 * * *$ & 0.008 \\
\hline$\beta_{C D S O}$ & -0.267 & 0.847 & $1.462 * * *$ & $1.604 * * *$ & $-2.383 *$ & -0.330 & $-1.910 * * *$ & $-1.523 * * *$ \\
\hline$\beta_{S P R}$ & -0.605 & $-0.283 *$ & -0.250 & -0.028 & -0.693 & $-0.185 *$ & $-0.218 * *$ & -0.030 \\
\hline$\beta_{E U R O M} 3$ & 0.001 & $0.010 * * *$ & 0.224 & $0.967 * *$ & 0.001 & $0.014 * * *$ & $1.412 * *$ & $1.181 * *$ \\
\hline ECB Dummies & - & - & yes & yes & - & - & yes & yes \\
\hline $\operatorname{Adj}-R^{2}$ & $1.07 \%$ & $13.62 \%$ & $19.03 \%$ & $6.39 \%$ & $1.71 \%$ & $12.79 \%$ & $10.61 \%$ & $4.02 \%$ \\
\hline Per/Cross-sec & $643 / 73$ & $609 / 84$ & $513 / 98$ & $507 / 111$ & $722 / 68$ & $609 / 75$ & $513 / 86$ & $507 / 108$ \\
\hline \multirow[t]{2}{*}{$\# O b s$} & 30,455 & 35,932 & 36,737 & 43,689 & 33,323 & 37,427 & 36,464 & 42,724 \\
\hline & \multicolumn{4}{|c|}{ Panel C: High Risk Countries (Italy, Ireland, Spain and Portugal) } & \multicolumn{4}{|c|}{ Panel D: Greece } \\
\hline Coefficient & $\begin{array}{l}\text { Pre-crisis } \\
\text { period }\end{array}$ & $\begin{array}{l}\text { Subprime crisis } \\
\text { period }\end{array}$ & $\begin{array}{l}\text { Sovereign crisis } \\
\text { period I }\end{array}$ & $\begin{array}{l}\text { Sovereign crisis } \\
\text { period II }\end{array}$ & $\begin{array}{l}\text { Pre-crisis } \\
\text { period }\end{array}$ & $\begin{array}{c}\text { Subprime crisis } \\
\text { period }\end{array}$ & $\begin{array}{c}\text { Sovereign crisis } \\
\text { period I }\end{array}$ & $\begin{array}{c}\text { Sovereign crisis } \\
\text { period II }\end{array}$ \\
\hline$\beta_{E Q T}$ & -0.015 & $-0.013 * *$ & $0.098 * * *$ & $0.170 * * *$ & $-0.013 * *$ & $0.020 * * *$ & $0.175 * * *$ & NA \\
\hline$\beta_{C D S O}$ & -0.467 & $-0.916 * * *$ & $-2.121 * * *$ & $-2.506 * * *$ & 0.640 & $-1.976 * * *$ & $-2.354 * * *$ & NA \\
\hline$\beta_{S P R}$ & -1.429 & $-0.445 * * *$ & $-0.118 * * *$ & -0.009 & -0.659 & $-0.116 * * *$ & $-0.072 * * *$ & NA \\
\hline$\beta_{\text {EURO M3 }}$ & 0.002 & $0.011 * * *$ & $1.181 *$ & -0.255 & $0.002 *$ & $0.014 * * *$ & -0.911 & NA \\
\hline ECB Dummies & - & - & yes & yes & - & - & yes & - \\
\hline $\operatorname{Adj}-R^{2}$ & $0.73 \%$ & $8.15 \%$ & $27.58 \%$ & $36.95 \%$ & $1.13 \%$ & $9.71 \%$ & $31.92 \%$ & NA \\
\hline Per/Cross-sec & $722 / 81$ & $609 / 105$ & $513 / 119$ & $507 / 140$ & $722 / 26$ & $609 / 26$ & $390 / 24$ & $N A$ \\
\hline$\# O b s$ & 41,646 & 45,175 & 50,419 & 54,385 & 13,721 & 12,359 & 5,007 & $N A$ \\
\hline
\end{tabular}
are used. $* * * * *$, and $*$ represent statistical significance at the $1 \%, 5 \%$, and $10 \%$ level, respectively. 


\section{Table VII}

\section{Determinants of Excess Sovereign Bond Returns with Flights-to-Safety}

This table reports panel regression coefficients for the following model:

$$
\mathrm{RB}_{\mathrm{i}, \mathrm{cr}, \mathrm{t}}-\mathrm{RECB}_{\mathrm{t}}=\mathrm{c}+\beta_{\mathrm{EQT}}\left(\mathrm{EQT}_{\mathrm{cr}, \mathrm{t}}-\mathrm{RECB}_{\mathrm{t}}\right)+\beta_{\mathrm{CDSO}} \Delta \mathrm{CDSO}_{\mathrm{cr}, \mathrm{t}}+\beta_{\mathrm{SPR}} \Delta \mathrm{Spr}_{\mathrm{i}, \mathrm{cr}, \mathrm{t}}+\beta_{\mathrm{FTS}} \mathrm{FTS}_{\mathrm{cr}, \mathrm{t}}+\varepsilon_{\mathrm{i}, \mathrm{cr}, \mathrm{t}}
$$

where $\mathrm{RB}_{\mathrm{i}, \mathrm{cr}, \mathrm{t}}$ denotes the mid-price return for bond i issued by country cr on day $\mathrm{t}, \mathrm{RECB}_{\mathrm{t}}$ represents the 3 month ECB yield, $\mathrm{EQT}_{\mathrm{cr}, \mathrm{t}}$ is the country specific stock index return, $\Delta \mathrm{CDSO}_{\mathrm{cr}, \mathrm{t}}$ is the change in country specific 5 year CDS spreads orthogonalized with respect to the other regressors, $\Delta \operatorname{Spr}_{\mathrm{i}, \mathrm{cr}, \mathrm{t}}$ is the change in bond specific proportional bid-ask spread, Local FTS $c r, t$ is a dummy variable that takes a value of 1 on days when a flight-to-safety episode is observed. A flight-to-safety episode occurs when the return of the country specific $10 \mathrm{Y}$ bond portfolio $>2 *$ StDev(10Y bond portfolio return, $2003-2013$ ) and the return of the stock market return <-2*StDev(stock market return, $2003-2013$ ). We employ daily observations. For each sub-period, regressions variables are winsorized at $1 \%$ and $99 \%$ taking into account all time-series observations demeaned at the bond level. Sub-periods are from 01 Oct 2004 to 31 Jul 2007 for the pre-crisis, from 01 Aug 2007 to 31 Dec 2009 for the subprime crisis; the sovereign crisis is split into two parts, from 01 Jan 2010 to 30 Dec 2011 and between 01 Jan 2012 to 31 Dec 2013 . White (1980) cross-section standard errors and covariances are used. ${ }^{* *}, * *$, and $*$ represent statistical significance at the $1 \%, 5 \%$, and $10 \%$ level, respectively.

\begin{tabular}{|c|c|c|c|c|c|c|c|c|}
\hline & \multicolumn{4}{|c|}{ Panel A: Low Risk Countries (Germany, Netherlands and Finland) } & \multicolumn{4}{|c|}{ Panel B: Medium Risk Countries (France, Austria and Belgium) } \\
\hline Coefficient & $\begin{array}{l}\text { Pre-crisis } \\
\text { period }\end{array}$ & $\begin{array}{l}\text { Subprime crisis } \\
\text { period }\end{array}$ & $\begin{array}{l}\text { Sovereign crisis } \\
\text { period I }\end{array}$ & $\begin{array}{l}\text { Sovereign crisis } \\
\text { period II }\end{array}$ & $\begin{array}{l}\text { Pre-crisis } \\
\text { period }\end{array}$ & $\begin{array}{l}\text { Subprime crisis } \\
\text { period }\end{array}$ & $\begin{array}{l}\text { Sovereign crisis } \\
\text { period I }\end{array}$ & $\begin{array}{c}\text { Sovereign crisis } \\
\text { period II }\end{array}$ \\
\hline$\beta_{E Q T}$ & $-0.024 * * *$ & $-0.055 * * *$ & $-0.094 * * *$ & $-0.068 * * *$ & $-0.033 * * *$ & $-0.054 * * *$ & $-0.044 * * *$ & 0.010 \\
\hline$\beta_{C D S O}$ & -0.283 & 0.835 & $1.464 * * *$ & $1.511 * * *$ & $-2.389 *$ & -0.480 & $-1.919 * * *$ & $-1.649 * * *$ \\
\hline$\beta_{S P R}$ & -0.623 & -0.241 & -0.239 & -0.046 & -0.704 & -0.152 & $-0.211 * *$ & -0.026 \\
\hline$\beta_{F T S}$ & $\mathrm{Na}$ & $24.545 * * *$ & $19.287 * * *$ & $\mathrm{Na}$ & $\mathrm{Na}$ & $36.858 * * *$ & $44.259 * * *$ & $\mathrm{Na}$ \\
\hline $\operatorname{Adj}-R^{2}$ & $1.29 \%$ & $12.84 \%$ & $19.39 \%$ & $6.14 \%$ & $1.91 \%$ & $11.16 \%$ & $10.74 \%$ & $3.57 \%$ \\
\hline Per/Cross-sec & $643 / 73$ & $609 / 84$ & $513 / 98$ & $507 / 111$ & $722 / 68$ & $609 / 75$ & $513 / 86$ & $507 / 108$ \\
\hline \multirow[t]{2}{*}{ \#Obs } & 30,455 & 35,932 & 36,737 & 43,689 & 33,323 & 37,427 & 36,464 & 42,724 \\
\hline & \multicolumn{4}{|c|}{ Panel C: High Risk Countries (Italy, Ireland, Spain and Portugal) } & \multicolumn{4}{|c|}{ Panel D: Greece } \\
\hline Coefficient & $\begin{array}{l}\text { Pre-crisis } \\
\text { period }\end{array}$ & $\begin{array}{c}\text { Subprime crisis } \\
\text { period }\end{array}$ & $\begin{array}{c}\text { Sovereign crisis } \\
\text { period I }\end{array}$ & $\begin{array}{l}\text { Sovereign crisis } \\
\text { period II }\end{array}$ & $\begin{array}{l}\text { Pre-crisis } \\
\text { period }\end{array}$ & $\begin{array}{c}\text { Subprime crisis } \\
\text { period }\end{array}$ & $\begin{array}{l}\text { Sovereign crisis } \\
\text { period I }\end{array}$ & $\begin{array}{c}\text { Sovereign crisis } \\
\text { period II }\end{array}$ \\
\hline$\beta_{E Q T}$ & $-0.024 * * *$ & $-0.037 * * *$ & $0.097 * * *$ & $0.171 * * *$ & $-0.018 * * *$ & $0.097 * * *$ & $0.185 * * *$ & NA \\
\hline$\beta_{C D S O}$ & -0.454 & $-0.901 * * *$ & $-2.131 * * *$ & $-2.517 * * *$ & 0.669 & $-2.131 * * *$ & $-2.443 * * *$ & NA \\
\hline$\beta_{S P R}$ & -1.442 & $-0.410 * * *$ & $-0.113 * * *$ & -0.009 & -0.642 & $-0.113 * * *$ & $-0.081 * * *$ & NA \\
\hline$\beta_{F T S}$ & $N a$ & $49.404 * * *$ & $137.507 * * *$ & $N a$ & $N a$ & $137.507 * * *$ & $594.467 * * *$ & $N a$ \\
\hline $\operatorname{Adj}-R^{2}$ & $0.82 \%$ & $6.57 \%$ & $27.23 \%$ & $36.90 \%$ & $1.01 \%$ & $27.23 \%$ & $31.37 \%$ & NA \\
\hline Per/Cross-sec & $722 / 81$ & $609 / 105$ & $513 / 119$ & $507 / 140$ & $722 / 26$ & $513 / 119$ & $390 / 24$ & $N A$ \\
\hline \#Obs & 41,646 & 45,175 & 50,419 & 54,385 & 13,721 & 50,419 & 5,007 & $N A$ \\
\hline
\end{tabular}


Table IX

\section{Determinants of Excess Sovereign Bond Returns: International Risk Factor and Libor-OIS Spread}

This table shows panel regression coefficients for the following model:

$$
R B_{i, c r, t}-R E C B_{t}=c+\beta_{E Q T}\left(E Q T_{c r, t}-R E C B_{t}\right)+\beta_{C D S O} \Delta C D S O_{c r, t}+\beta_{S P R} \Delta S p r_{i, c r, t}+\beta_{I N T R} \Delta I n t R_{t}+\beta_{L O I S} \Delta L O I S_{t}+\varepsilon_{i, c r, t}
$$

where $\mathrm{RB}_{\mathrm{i}, \mathrm{cr}, \mathrm{t}}$ denotes the bond mid-price return on day $\mathrm{t}$ for bond $\mathrm{i}$ issued by country cr, RECB $\mathrm{R}_{\mathrm{t}}$ represents the 3 month ECB yield, EQT $\mathrm{Er}_{\text {cr,t }}$ is the country specific stock index return, $\triangle \mathrm{CDSO}_{\text {cr,t }}$ is the change in country specific 5 year CDS spreads orthogonalized with respect to all the other regressors, $\Delta$ Spr $_{i, c, t}$ is the change in bond specific proportional bid-ask spread, $\Delta$ Int $_{t}$ is the change in the international risk factor, and $\Delta \mathrm{LOIS}_{\mathrm{t}}$ is the change in the Libor-OIS spread. For each sub-period, regressions variables are winsorized at $1 \%$ and $99 \%$ taking into account all time-series observations demeaned at the bond level. We employ daily observations. Sub-periods are from 01 Oct 2004 to 31 Jul 2007 for the pre-crisis, from 01 Aug 2007 to 31 Dec 2009 for the subprime crisis; the sovereign crisis is split into two parts, from 01 Jan 2010 to 30 Dec 2011 and from 01 Jan 2012 to 31 Dec 2013. White (1980) cross-section standard errors and covariances are used. ***, $* *$, and $*$ represent statistical significance at the $1 \%, 5 \%$, and $10 \%$ level, respectively.

\begin{tabular}{|c|c|c|c|c|c|c|c|c|}
\hline \multirow[b]{2}{*}{ Coefficient } & \multicolumn{4}{|c|}{ Panel A: Low Risk Countries (Germany, Netherlands and Finland) } & \multicolumn{4}{|c|}{ Panel B: Medium Risk Countries (France, Austria and Belgium) } \\
\hline & $\begin{array}{l}\text { Pre-crisis } \\
\text { period }\end{array}$ & $\begin{array}{l}\text { Subprime crisis } \\
\text { period }\end{array}$ & $\begin{array}{l}\text { Sovereign crisis } \\
\text { period I }\end{array}$ & $\begin{array}{l}\text { Sovereign crisis } \\
\text { period II }\end{array}$ & $\begin{array}{l}\text { Pre-crisis } \\
\text { period }\end{array}$ & $\begin{array}{l}\text { Subprime crisis } \\
\text { period }\end{array}$ & $\begin{array}{c}\text { Sovereign crisis } \\
\text { period I }\end{array}$ & $\begin{array}{c}\text { Sovereign crisis } \\
\text { period II }\end{array}$ \\
\hline$\beta_{E Q T}$ & $-0.018 * * *$ & $-0.054 * * *$ & $-0.093 * * *$ & $-0.067 * * *$ & $-0.027 * * *$ & $-0.051 * * *$ & $-0.045 * * *$ & 0.010 \\
\hline$\beta_{C D S O}$ & -0.648 & 0.735 & $1.207 * *$ & $1.413 * * *$ & -1.589 & -0.439 & $-2.010 * * *$ & $-1.694 * * *$ \\
\hline$\beta_{S P R}$ & -0.895 & -0.252 & -0.294 & -0.087 & -0.872 & -0.160 & $-0.239 * * *$ & -0.051 \\
\hline$\beta_{I N T R}$ & $-0.963 * * *$ & $-0.566 * * *$ & 0.308 & -0.127 & $-1.311 * * *$ & $-0.711 * * *$ & -0.119 & 0.328 \\
\hline$\beta_{\text {LOIS }}$ & $3.871 * * *$ & $1.221 * * *$ & $2.241 * * *$ & $4.640 * * *$ & $4.519 * * *$ & $1.420 * * *$ & $2.385 * * *$ & $4.302 * *$ \\
\hline $\operatorname{Adj}-R^{2}$ & $7.12 \%$ & $14.22 \%$ & $20.74 \%$ & $7.00 \%$ & $8.23 \%$ & $13.00 \%$ & $11.94 \%$ & $4.60 \%$ \\
\hline Per/Cross-sec & $643 / 73$ & $609 / 84$ & $513 / 98$ & $507 / 111$ & $722 / 68$ & $609 / 75$ & $513 / 86$ & $507 / 108$ \\
\hline \multirow[t]{2}{*}{ \#Obs } & 30,455 & 35,932 & 36,737 & 43,689 & 33,323 & 37,427 & 36,464 & 42,724 \\
\hline & \multicolumn{4}{|c|}{ Panel C: High Risk Credit Countries (Italy, Ireland, Spain and Portugal) } & \multicolumn{4}{|c|}{ Panel D: Greece } \\
\hline Coefficient & $\begin{array}{l}\text { Pre-crisis } \\
\text { period }\end{array}$ & $\begin{array}{c}\text { Subprime crisis } \\
\text { period }\end{array}$ & $\begin{array}{c}\text { Sovereign crisis } \\
\text { period I }\end{array}$ & $\begin{array}{c}\text { Sovereign crisis } \\
\text { period II }\end{array}$ & $\begin{array}{l}\text { Pre-crisis } \\
\text { period }\end{array}$ & $\begin{array}{c}\text { Subprime crisis } \\
\text { period }\end{array}$ & $\begin{array}{c}\text { Sovereign crisis } \\
\text { period I }\end{array}$ & $\begin{array}{c}\text { Sovereign crisis } \\
\text { period II }\end{array}$ \\
\hline$\beta_{E Q T}$ & $-0.019 * *$ & $-0.033 * * *$ & $0.099 * * *$ & $0.171 * * *$ & $-0.016 * * *$ & 0.005 & $0.183 * * *$ & NA \\
\hline$\beta_{\text {CDSO }}$ & -0.049 & $-0.949 * * *$ & $-2.183 * * *$ & $-2.518 * * *$ & 0.752 & $-1.978 * * *$ & $-2.442 * * *$ & NA \\
\hline$\beta_{S P R}$ & $-1.449 *$ & $-0.435 * * *$ & $-0.116 * * *$ & -0.009 & -0.723 & $-0.104 * *$ & $-0.078 * * *$ & NA \\
\hline$\beta_{I N T R}$ & $-1.121 * * *$ & $-0.669 * * *$ & 0.344 & 0.236 & $-1.082 * * *$ & $-0.719 * * *$ & -0.673 & NA \\
\hline$\beta_{\text {LOIS }}$ & $3.969 * * *$ & $1.241 * * *$ & 0.822 & -2.318 & $3.698 * * *$ & $1.146 * * *$ & -1.763 & NA \\
\hline $\operatorname{Adj}-R^{2}$ & $6.94 \%$ & $8.89 \%$ & $27.43 \%$ & $36.92 \%$ & $7.37 \%$ & $8.50 \%$ & $31.28 \%$ & NA \\
\hline Per/Cross-sec & $722 / 81$ & $609 / 105$ & $513 / 119$ & $507 / 140$ & $722 / 26$ & $609 / 26$ & $390 / 24$ & $N A$ \\
\hline$\# O b s$ & 41,646 & 45,175 & 50,419 & 54,385 & 13,721 & 12,359 & 5,007 & $N A$ \\
\hline
\end{tabular}


Table X

Correlation of Excess Sovereign Bond Returns and the Term Factor

This table reports the correlation of the term factor, and its long term component, with country specific excess sovereign bond returns. The term factor is the difference between the return of a sovereign bond portfolio with a 10 year average maturity and the 3 month ECB rate. The term factor's long term component is the return of the sovereign bond portfolio with a 10 year average maturity. Short, medium and long denote bonds with a remaining time-to-maturity of less than 3 years, between 3 and 7 years, and above 7 years, respectively. Correlations are estimate over the full sample period from 01 Oct 2004 to 31 Dec 2013.

\begin{tabular}{|c|c|c|c|c|c|c|}
\hline & \multicolumn{3}{|c|}{ Term Factor } & \multicolumn{3}{|c|}{$\begin{array}{c}\text { Term Factor's } \\
\text { Long Term Component }\end{array}$} \\
\hline & $\begin{array}{c}\text { Short } \\
\text { Maturity }\end{array}$ & $\begin{array}{l}\text { Medium } \\
\text { Maturity }\end{array}$ & $\begin{array}{c}\text { Long } \\
\text { Maturity }\end{array}$ & $\begin{array}{c}\text { Short } \\
\text { Maturity }\end{array}$ & $\begin{array}{l}\text { Medium } \\
\text { Maturity }\end{array}$ & $\begin{array}{c}\text { Long } \\
\text { Maturity }\end{array}$ \\
\hline Germany & $57.44 \%$ & $89.19 \%$ & $90.79 \%$ & $57.45 \%$ & $89.19 \%$ & $90.78 \%$ \\
\hline Netherlands & $55.09 \%$ & $88.50 \%$ & $89.44 \%$ & $55.08 \%$ & $88.48 \%$ & $89.42 \%$ \\
\hline Finland & $57.40 \%$ & $85.93 \%$ & $93.65 \%$ & $57.36 \%$ & $85.92 \%$ & $93.59 \%$ \\
\hline France & $57.89 \%$ & $87.02 \%$ & $87.54 \%$ & $57.87 \%$ & $87.01 \%$ & $87.51 \%$ \\
\hline Austria & $51.27 \%$ & $83.33 \%$ & $88.22 \%$ & $51.26 \%$ & $83.33 \%$ & $88.20 \%$ \\
\hline Belgium & $56.07 \%$ & $82.69 \%$ & $86.53 \%$ & $56.07 \%$ & $82.69 \%$ & $86.53 \%$ \\
\hline Italy & $68.14 \%$ & $90.49 \%$ & $92.07 \%$ & $68.12 \%$ & $90.48 \%$ & $92.07 \%$ \\
\hline Spain & $64.31 \%$ & $88.94 \%$ & $91.68 \%$ & $64.29 \%$ & $88.94 \%$ & $91.67 \%$ \\
\hline Portugal & $60.47 \%$ & $83.52 \%$ & $85.66 \%$ & $60.46 \%$ & $83.52 \%$ & $85.66 \%$ \\
\hline Ireland & $48.94 \%$ & $72.67 \%$ & $83.81 \%$ & $48.94 \%$ & $72.67 \%$ & $83.81 \%$ \\
\hline Greece & $42.81 \%$ & $65.68 \%$ & $54.29 \%$ & $42.92 \%$ & $65.69 \%$ & $54.28 \%$ \\
\hline
\end{tabular}


This table reports panel regression coefficients for the following model:

Table XI

\section{Maturity Effects}

$R B_{i, c r, t}-R E C B_{t}=c+\beta_{E Q T_{S}}\left(E Q T_{c r, t}-R E C B_{t}\right) * D U M_{S M L}+\beta_{E Q T_{M}}\left(E Q T_{i, c r, t}-R E C B_{t}\right) * D U M_{M E D}+\beta_{E Q T_{L}}\left(E Q T_{i, c r, t}-R E C B_{t}\right) * D U M_{L N G}+\beta_{C D S O} \Delta C D S O_{c r, t}+\beta_{S P R} \Delta S p r_{i, c r, t}+\varepsilon_{i, c r, t}$

where $\mathrm{RB}_{\mathrm{i}, \mathrm{c}, \mathrm{t}}$ denotes the mid-price return for bond $\mathrm{i}$ issued by country cr on day $\mathrm{t}, \mathrm{RECB}_{\mathrm{t}}$ represents the 3 month ECB yield, EQT $\mathrm{E}_{\text {cr, } \mathrm{t}}$ is the country specific stock index return, $\triangle C D S O_{c r, t}$ is the change in country specific 5 year CDS spreads orthogonalized with respect to all the other regressors, $\Delta$ Spr $_{i, c, t}$ is the change in bond specific percentage bid-ask spread. We employ daily observations. For each sub-period, regressions variables are winsorized at $1 \%$ and $99 \%$ taking into account all time-series observations demeaned at the bond level. Sub-periods are from 01 Oct 2004 to 31 Jul 2007 for the pre-crisis, from 01 Aug 2007 to 31 Dec 2009 for the subprime crisis; the sovereign crisis is split into two parts, from 01 Jan 2010 to 30 Dec 2011 and from 01 Jan 2012 to 31 Dec 2013 . White (1980) cross-section standard errors and covariances are used. $* * *, * *$, and $*$ represent statistical significance at the $1 \%, 5 \%$, and $10 \%$ level, respectively.

\begin{tabular}{|c|c|c|c|c|c|c|c|c|}
\hline \multirow[b]{2}{*}{ Coefficient } & \multicolumn{4}{|c|}{ Panel A: Low Risk Countries (Germany, Netherlands and Finland) } & \multicolumn{4}{|c|}{ Panel B: Medium Risk Countries (France, Austria and Belgium) } \\
\hline & $\begin{array}{l}\text { Pre-crisis } \\
\text { period }\end{array}$ & $\begin{array}{l}\text { Subprime crisis } \\
\text { period }\end{array}$ & $\begin{array}{l}\text { Sovereign crisis } \\
\text { period I }\end{array}$ & $\begin{array}{c}\text { Sovereign crisis } \\
\text { period II }\end{array}$ & $\begin{array}{l}\text { Pre-crisis } \\
\text { period }\end{array}$ & $\begin{array}{l}\text { Subprime crisis } \\
\text { period }\end{array}$ & $\begin{array}{l}\text { Sovereign crisis } \\
\text { period I }\end{array}$ & $\begin{array}{c}\text { Sovereign crisis } \\
\text { period II }\end{array}$ \\
\hline$\beta_{E Q T_{S}}$ & $-0.006 * * *$ & $-0.020 * * *$ & $-0.019 * * *$ & $-0.006 * * *$ & $-0.008 * * *$ & $-0.020 * * *$ & $-0.007 *$ & $0.004 *$ \\
\hline$\beta_{E Q T_{M}}$ & $-0.028 * * *$ & $-0.066 * * *$ & $-0.089 * * *$ & $-0.045 * * *$ & $-0.031 * * *$ & $-0.058 * * *$ & $-0.028 * * *$ & $0.015 *$ \\
\hline$\beta_{E Q T_{L}}$ & $-0.044 * * *$ & $-0.099 * * *$ & $-0.215 * * *$ & $-0.142 * * *$ & $-0.048 * * *$ & $-0.076 * * *$ & $-0.107 * * *$ & 0.010 \\
\hline $\operatorname{Adj-} R^{2}$ & $1.92 \%$ & $15.55 \%$ & $30.67 \%$ & $10.31 \%$ & $2.20 \%$ & $11.62 \%$ & $13.12 \%$ & $3.77 \%$ \\
\hline Per/Cross-sec & $643 / 73$ & $609 / 84$ & $513 / 98$ & $507 / 111$ & $722 / 68$ & $609 / 75$ & $513 / 86$ & $507 / 108$ \\
\hline \multirow[t]{2}{*}{ \#Obs } & 30,455 & 35,932 & 36,737 & 43,689 & 33,323 & 37,427 & 36,464 & 42,724 \\
\hline & \multicolumn{4}{|c|}{ Panel C: High Risk Countries (Italy, Ireland, Spain and Portugal) } & \multicolumn{4}{|c|}{ Panel D: Greece } \\
\hline Coefficient & $\begin{array}{l}\text { Pre-crisis } \\
\text { period }\end{array}$ & $\begin{array}{l}\text { Subprime crisis } \\
\text { period }\end{array}$ & $\begin{array}{l}\text { Sovereign crisis } \\
\text { period I }\end{array}$ & $\begin{array}{c}\text { Sovereign crisis } \\
\text { period II }\end{array}$ & $\begin{array}{l}\text { Pre-crisis } \\
\text { period }\end{array}$ & $\begin{array}{l}\text { Subprime crisis } \\
\text { period }\end{array}$ & $\begin{array}{l}\text { Sovereign crisis } \\
\text { period I }\end{array}$ & $\begin{array}{l}\text { Sovereign crisis } \\
\text { period II }\end{array}$ \\
\hline$\beta_{E Q T_{S}}$ & $-0.007 * * *$ & $-0.016 * * *$ & $0.052 * * *$ & $0.068 * * *$ & $-0.005 * * *$ & -0.001 & $0.110 * * *$ & NA \\
\hline$\beta_{E Q T_{M}}$ & $-0.026 * * *$ & $-0.043 * * *$ & $0.099 * * *$ & $0.176 * * *$ & $-0.016 * * *$ & -0.002 & $0.214 * * *$ & NA \\
\hline$\beta_{E Q T_{L}}$ & $-0.038 * * *$ & $-0.052 * * *$ & $0.130 * * *$ & $0.261 * * *$ & $-0.031 * * *$ & 0.004 & $0.218 * * *$ & NA \\
\hline $\operatorname{Adj-} R^{2}$ & $1.00 \%$ & $7.01 \%$ & $28.12 \%$ & $40.74 \%$ & $1.37 \%$ & $6.57 \%$ & $31.67 \%$ & NA \\
\hline Per/Cross-sec & $722 / 81$ & $609 / 105$ & $513 / 119$ & $507 / 140$ & $722 / 26$ & $609 / 26$ & $390 / 24$ & $N A$ \\
\hline \#Obs & 41,646 & 45,175 & 50,419 & 54,385 & 13,721 & 12,359 & 5,007 & $N A$ \\
\hline
\end{tabular}


Table XII

\section{Determinants of Excess Sovereign Bond Returns: Schwarz (2016) Illiquidity Measure}

This table reports panel regression coefficients for the following model:

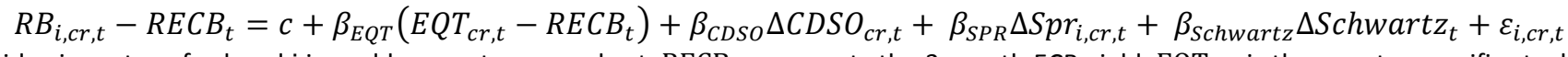

where $\mathrm{RB}_{\mathrm{i}, \mathrm{cr}, \mathrm{t}}$ denotes the mid-price return for bond $\mathrm{i}$ issued by country cr on day $\mathrm{t}, \mathrm{RECB}_{\mathrm{t}}$ represents the 3 month $\mathrm{ECB}$ yield, $\mathrm{EQT}_{\mathrm{cr}, \mathrm{t}}$ is the country specific stock index return, $\triangle \mathrm{CDSO}_{\mathrm{cr}, \mathrm{t}}$ is the change in country specific 5 year CDS spreads orthogonalized with respect to the other regressors, $\Delta \mathrm{Spr}_{\mathrm{i}, \mathrm{cr}, \mathrm{t}}$ is the change in bond specific proportional bid-ask spread, and $\Delta \mathrm{Schwarz}_{\mathrm{t}}$ refers to the change in yields between portfolios of $\mathrm{KfW}$ bonds and German sovereign bonds with an approximate time-to-maturity of 5 years (i.e. $4.5-5.5$ years). We employ daily observations. For each sub-period, regressions variables are winsorized at $1 \%$ and $99 \%$ taking into account all time-series observations demeaned at the bond level. Sub-periods are from 01 Oct 2004 to 31 Jul 2007 for the pre-crisis, from 01 Aug 2007 to 31 Dec 2009 for the subprime crisis; the sovereign crisis is split into two parts, from 01 Jan 2010 to 30 Dec 2011 and from 01 Jan 2012 to 31 Dec 2013 . White (1980) cross-section standard errors and covariances are used. ${ }^{* * *},{ }^{* *}$, and * represent statistical significance at the $1 \%, 5 \%$, and $10 \%$ level, respectively.

Panel A: Low Risk Countries (Germany, Netherlands and Finland)

Panel B: Medium Risk Countries (France, Austria and Belgium)

\begin{tabular}{|c|c|c|c|c|c|c|c|c|}
\hline Coefficient & $\begin{array}{l}\text { Pre-crisis } \\
\text { period }\end{array}$ & $\begin{array}{l}\text { Subprime crisis } \\
\text { period }\end{array}$ & $\begin{array}{c}\text { Sovereign crisis } \\
\text { period I }\end{array}$ & $\begin{array}{l}\text { Sovereign crisis } \\
\text { period II }\end{array}$ & $\begin{array}{l}\text { Pre-crisis } \\
\text { period }\end{array}$ & $\begin{array}{l}\text { Subprime crisis } \\
\text { period }\end{array}$ & $\begin{array}{l}\text { Sovereign crisis } \\
\text { period I }\end{array}$ & $\begin{array}{c}\text { Sovereign crisis } \\
\text { period II }\end{array}$ \\
\hline$\beta_{E Q T}$ & $-0.024 * * *$ & $-0.037 * * *$ & $-0.067 * * *$ & $-0.042 * * *$ & $-0.033 * * *$ & $-0.034 * * *$ & $-0.032 * * *$ & 0.006 \\
\hline$\beta_{C D S O}$ & -0.252 & 0.556 & $0.687 *$ & 0.367 & $-2.422 *$ & -0.502 & $-2.172 * * *$ & $-1.743 * * *$ \\
\hline$\beta_{S P R}$ & -0.648 & $-0.380 * *$ & -0.312 & -0.109 & -0.717 & $-0.258 * * *$ & $-0.223 * *$ & -0.013 \\
\hline$\beta_{\text {Schwarz }}$ & 0.733 & $4.873 * * *$ & $5.130 * * *$ & $4.064 * * *$ & 0.301 & $5.336 * * *$ & $2.965 * * *$ & -0.554 \\
\hline $\operatorname{Adj}-R^{2}$ & $1.31 \%$ & $21.68 \%$ & $26.74 \%$ & $10.33 \%$ & $1.91 \%$ & $20.15 \%$ & $13.33 \%$ & $3.66 \%$ \\
\hline Per/Cross-sec & $643 / 73$ & $609 / 84$ & $513 / 98$ & $507 / 111$ & $722 / 68$ & $609 / 75$ & $513 / 86$ & $507 / 108$ \\
\hline \multirow[t]{2}{*}{$\# O b s$} & 30,455 & 35,932 & 36,737 & 43,689 & 33,323 & 37,427 & 36,464 & 42,724 \\
\hline & \multicolumn{4}{|c|}{ Panel C: High Risk Countries (Italy, Ireland, Spain and Portugal) } & \multicolumn{4}{|c|}{ Panel D: Greece } \\
\hline Coefficient & $\begin{array}{l}\text { Pre-crisis } \\
\text { period }\end{array}$ & $\begin{array}{l}\text { Subprime crisis } \\
\text { period }\end{array}$ & $\begin{array}{c}\text { Sovereign crisis } \\
\text { period I }\end{array}$ & $\begin{array}{c}\text { Sovereign crisis } \\
\text { period II }\end{array}$ & $\begin{array}{l}\text { Pre-crisis } \\
\text { period }\end{array}$ & $\begin{array}{c}\text { Subprime crisis } \\
\text { period }\end{array}$ & $\begin{array}{l}\text { Sovereign crisis } \\
\text { period I }\end{array}$ & $\begin{array}{l}\text { Sovereign crisis } \\
\text { period II }\end{array}$ \\
\hline$\beta_{E Q T}$ & $-0.024 * * *$ & $-0.021 * * *$ & $0.075 * * *$ & $0.151 * * *$ & $-0.018 * * *$ & $0.012 *$ & $0.151 * * *$ & NA \\
\hline$\beta_{C D S O}$ & -0.449 & $-0.977 * * *$ & $-2.169 * * *$ & $-2.490 * * *$ & 0.657 & $-2.059 * * *$ & $-2.358 * * *$ & NA \\
\hline$\beta_{S P R}$ & -1.430 & $-0.482 * * *$ & $-0.115 * * *$ & -0.008 & -0.627 & $-0.122 * * *$ & $-0.070 * * *$ & NA \\
\hline$\beta_{\text {Schwarz }}$ & -0.204 & $3.728 * * *$ & $-3.259 * * *$ & $-4.376 * * *$ & -0.892 & $3.493 * * *$ & $-11.608 * * *$ & NA \\
\hline $\operatorname{Adj}-R^{2}$ & $0.82 \%$ & $12.06 \%$ & $27.06 \%$ & $36.95 \%$ & $1.05 \%$ & $10.67 \%$ & $31.05 \%$ & NA \\
\hline Per/Cross-sec & $722 / 81$ & $609 / 105$ & $513 / 119$ & $507 / 140$ & $722 / 26$ & $609 / 26$ & $390 / 24$ & $N A$ \\
\hline$\# O b s$ & 41,646 & 45,175 & 50,419 & 54,385 & 13,721 & 12,359 & 5,007 & $N A$ \\
\hline
\end{tabular}




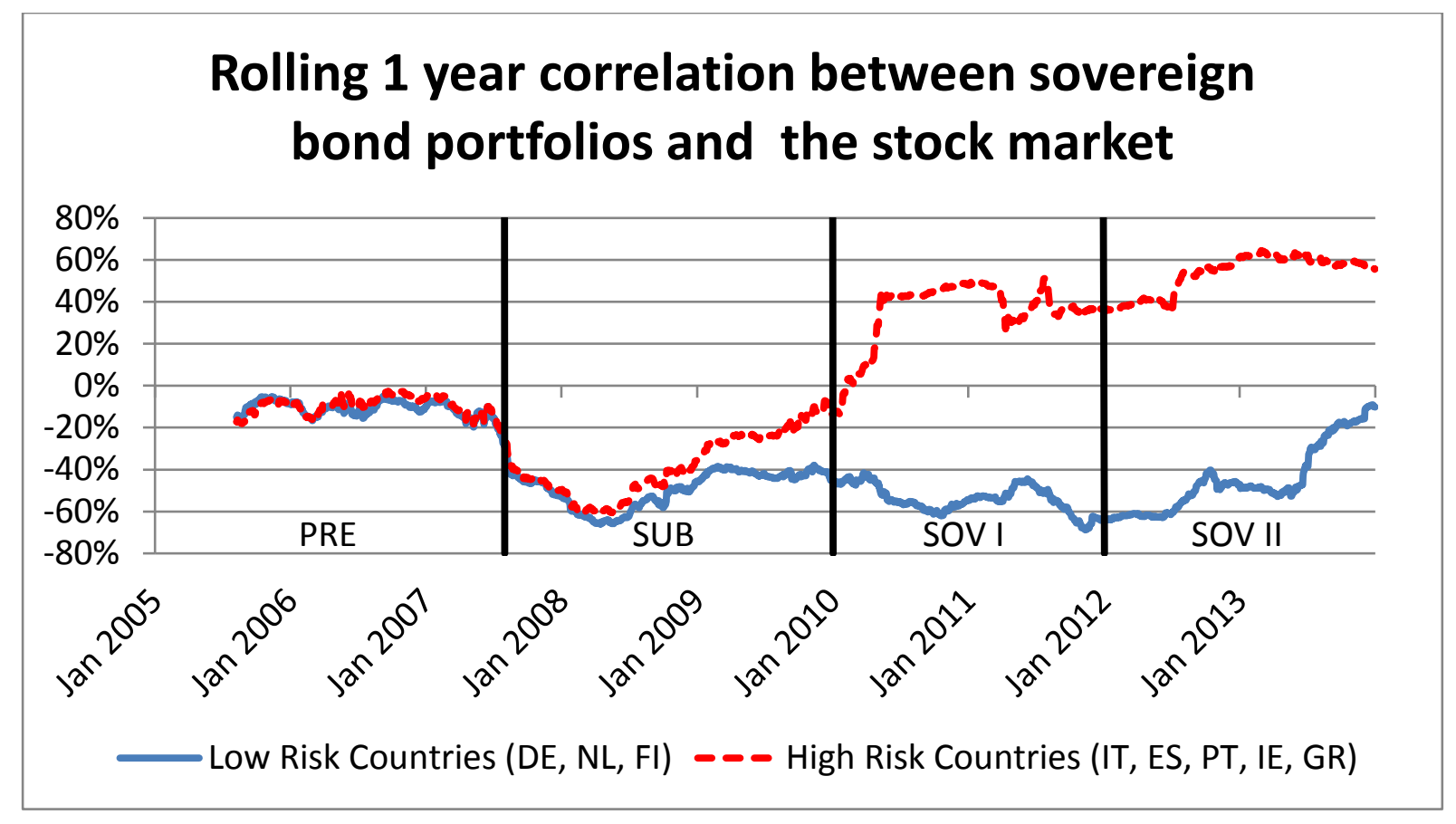

Figure I. Rolling 1 year correlation between sovereign bond portfolios and the stock market

This figure presents the rolling 1 year correlation between sovereign bond portfolios and stock market portfolio for different groups of Euro-zone countries depending on risk. Group bond/stock portfolio returns are obtained as an average of bond/stock portfolio returns belonging to the countries inside the group. Country-specific bond portfolio returns are estimated as return averages of all sovereign benchmark bonds of a country. Country-specific stock market returns are obtained from equity indices data for each Euro-zone country. Countries included are Germany (DE), the Netherlands (NL), Finland (FI), Italy (IT), Spain (ES), Portugal (PT), Ireland (IE), and Greece (GR). We employ daily observations. Sub-periods are 01 Oct 2004 to 31 Jul 2007 for the pre-crisis (PRE), 01 Aug 2007 and 31 Dec 2009 for the subprime crisis (SUB), 01 Jan 2010 to 30 Dec 2011 and 01 Jan 2012 to 31 Dec 2013 for the first (SOV I) and second (SOV II) part, respectively, of sovereign debt crisis. 


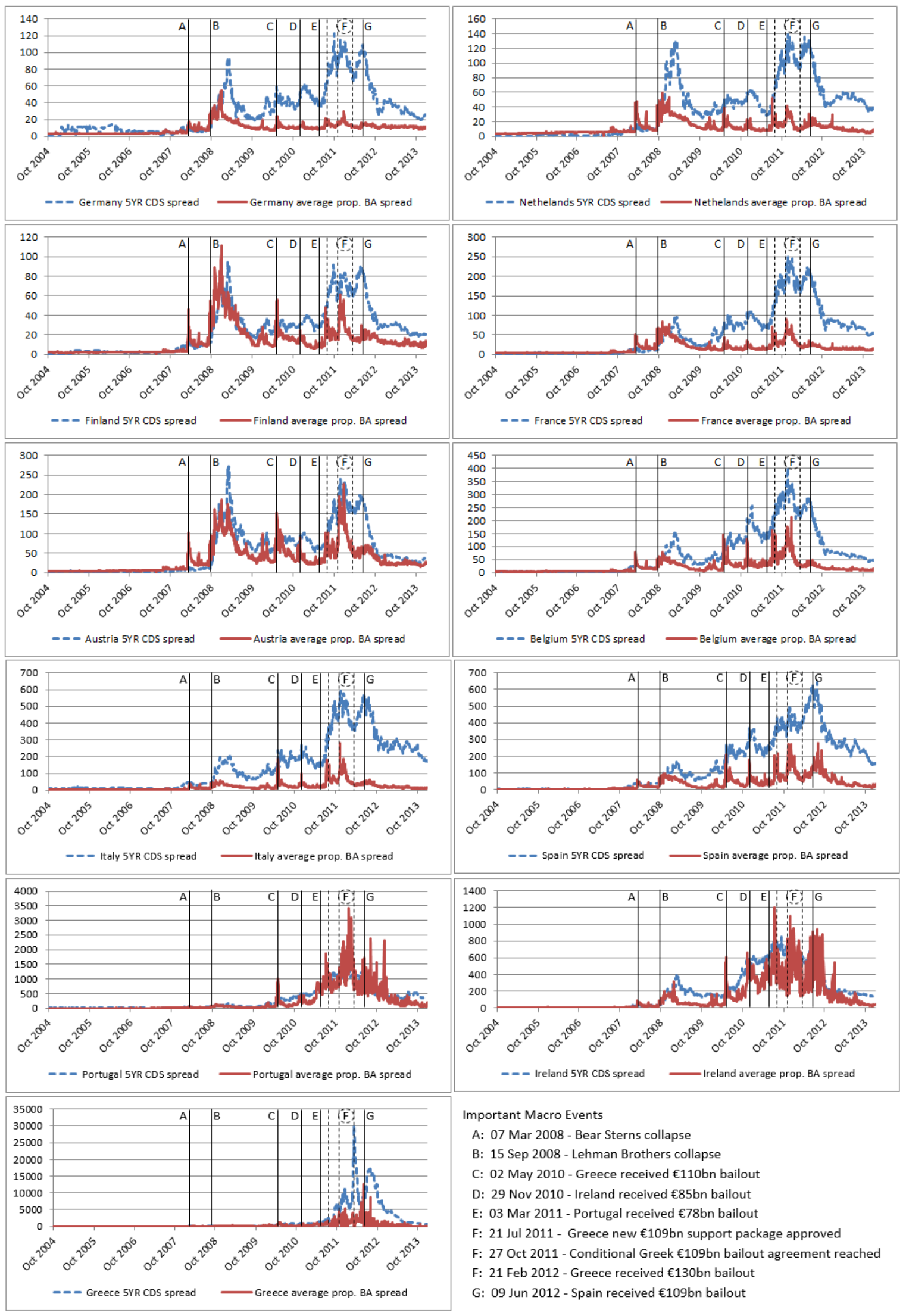

Figure II. Individual country 5 year CDS spreads and average proportional bid-ask spreads. This figure shows the daily 5 year CDS spreads and proportional bid-ask spreads for each Eurozone country from Oct 2004 to Dec 2013. All values are expressed in basis points. The vertical lines represent major global events. 

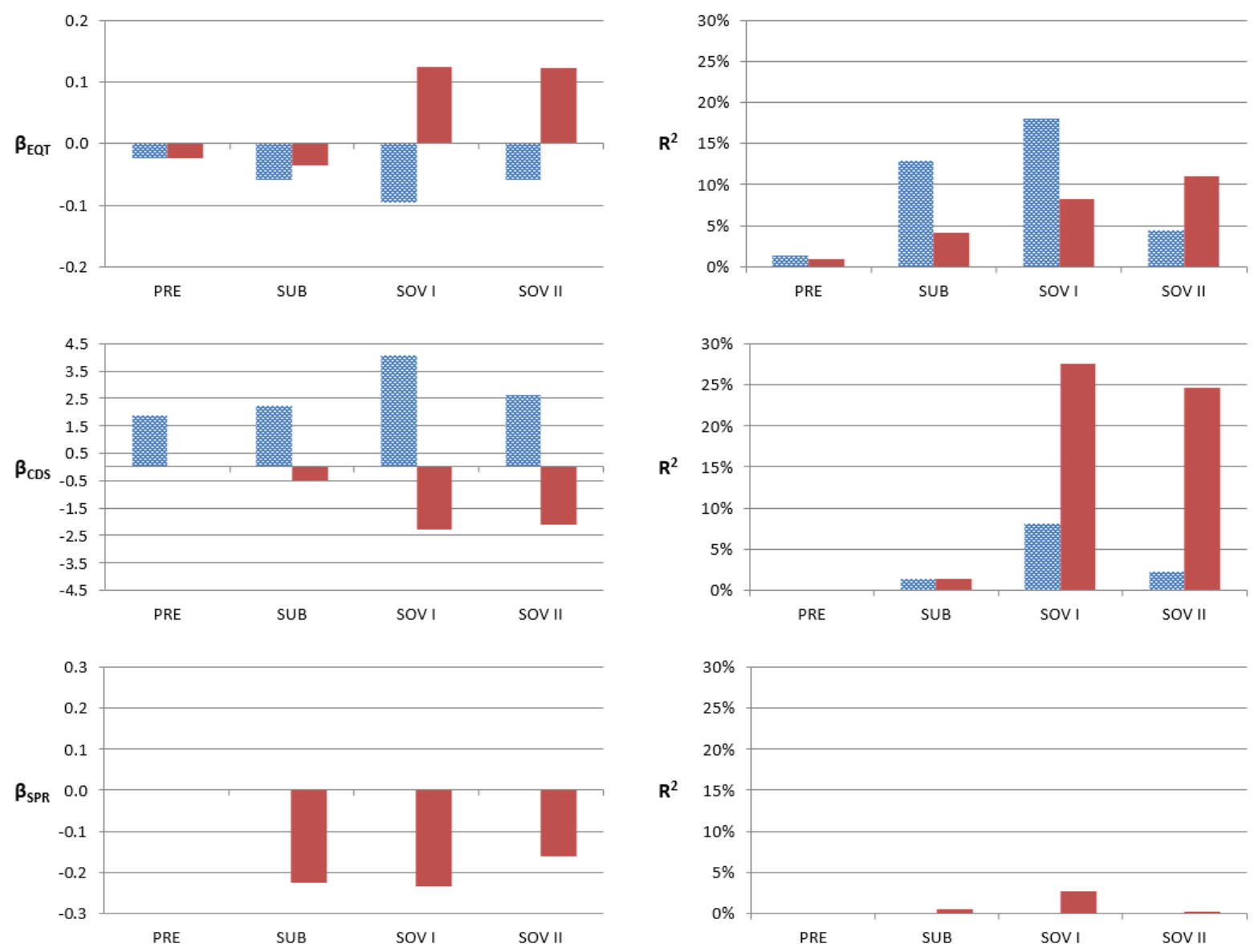

繬 Low Risk Countries (DE, NL, FI)

- High Risk Countries (IT, ES, PT, IE, GR)

Figure III. Univariate regressions of Excess Sovereign Bond Returns on Excess Stock Market Returns, Changes in 5 year CDS Spreads, and Changes in Bid-Ask Spreads

This figure reports the statistically significant coefficients (at 10\%) of the following panel regression model:

$$
R B_{i, c r, t}-R E C B_{t}=c+\beta X_{t}+\varepsilon_{i, c r, t}
$$

where $R B_{i, c r, t}$ represents the mid-price return at time $t$ of bond $i$ issued by country $c r, R E C B_{t}$ represents the 3 month ECB yield, and $X_{t}$ is equal to either the excess equity index return $\left(E Q T_{c r, t}-R E C B_{t}\right.$; top figure), the change of the country specific 5 year CDS spread $\left(\triangle C D S_{c r, t}\right.$; middle figure), or the change of the bond specific proportional bid-ask spread $\left(\Delta S p r_{i, c r, t}\right.$; bottom figure). Corresponding adjusted- $\mathrm{R}^{2} \mathrm{~s}$ are presented in the figures on the right. Countries included are Germany (DE), the Netherlands (NL), Finland (FI), Italy (IT), Spain (ES), Portugal (PT), Ireland (IE), and Greece (GR). We employ daily observations. For each sub-period, regressions variables are winsorized at $1 \%$ and $99 \%$ taking into account all timeseries observations demeaned at the bond level. Sub-periods are 01 Oct 2004 to 31 Jul 2007 for the pre-crisis, 01 Aug 2007 and 31 Dec 2009 for the subprime crisis; the sovereign crisis is split into two parts, 01 Jan 2010 to 30 Dec 2011 and between 01 Jan 2012 to 31 Dec 2013. White (1980) cross-section standard errors and covariance are used. 


\section{Realised CAPM Beta}

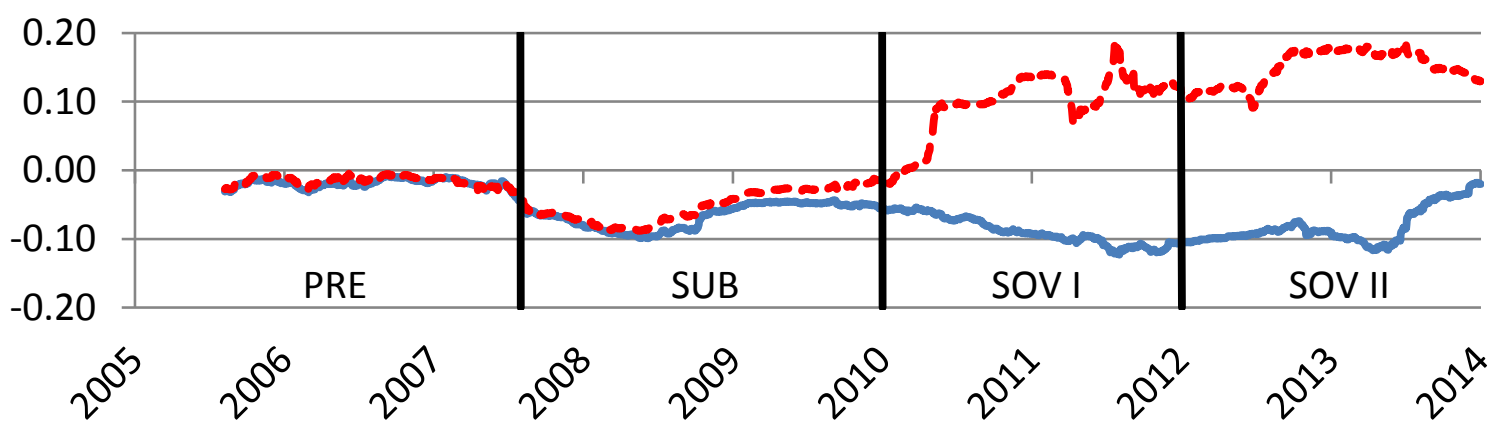

Conditional Equity Beta (200 bp CDS Dummy)

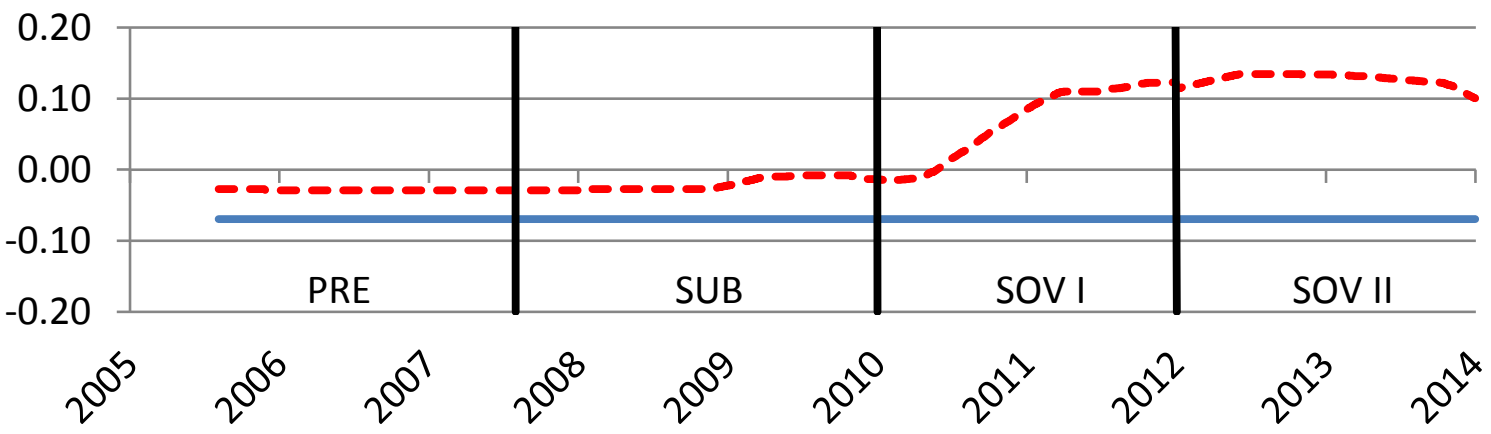

Conditional Equity Beta (macro fundamentals)

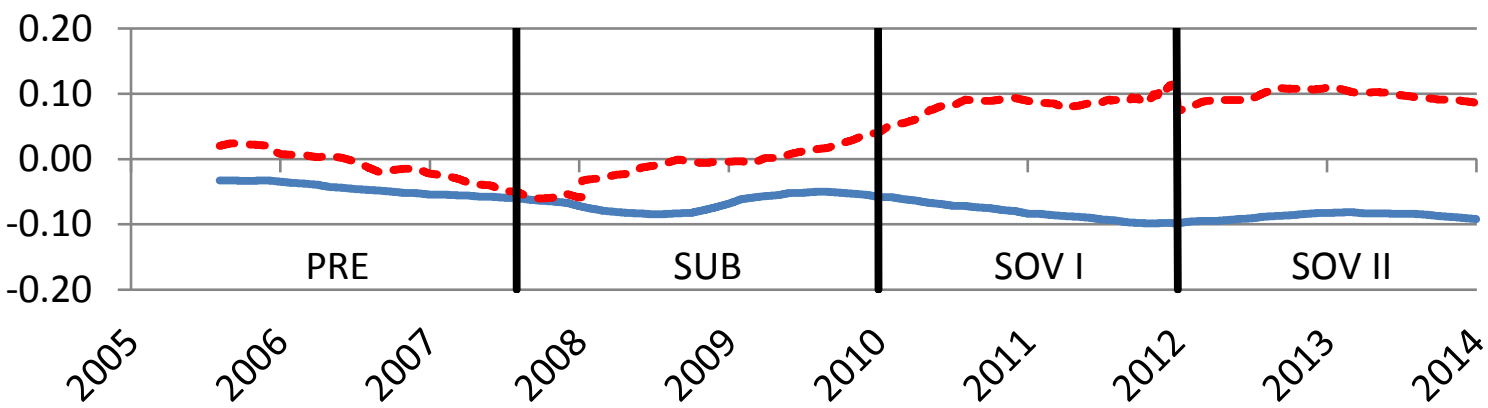

Low risk countries (DE, NL, FI) - - High Risk Countries (IT, ES, PT, IE, GR)

Figure IV. Conditional Equity Beta and Realised CAPM Beta

This figure reports the rolling 1 year cross-country averages of realised CAPM betas (top figure), of betas estimated with an interacted $200 \mathrm{bp}$ CDS dummy (middle figure), and of betas estimated with interacted macro-factors (bottom figure). Group bond/stock portfolio returns are obtained as an average of bond/stock portfolio returns belonging to the countries inside the group. Country-specific bond portfolio returns are estimated as return averages of all sovereign benchmark bonds of a country. Countries included are Germany (DE), the Netherlands (NL), Finland (FI), Italy (IT), Spain (ES), Portugal (PT), Ireland (IE), and Greece (GR). The base rate is the 3 month AAA ECB yield. We employ daily observations. Sub-periods are 01 Oct 2004 to $31 \mathrm{Jul} 2007$ for the pre-crisis (PRE), 01 Aug 2007 and 31 Dec 2009 for the subprime crisis (SUB), 01 Jan 2010 to 30 Dec 2011 and 01 Jan 2012 to 31 Dec 2013 for the first (SOV I) and second (SOV II) part, respectively, of the sovereign debt crisis. 

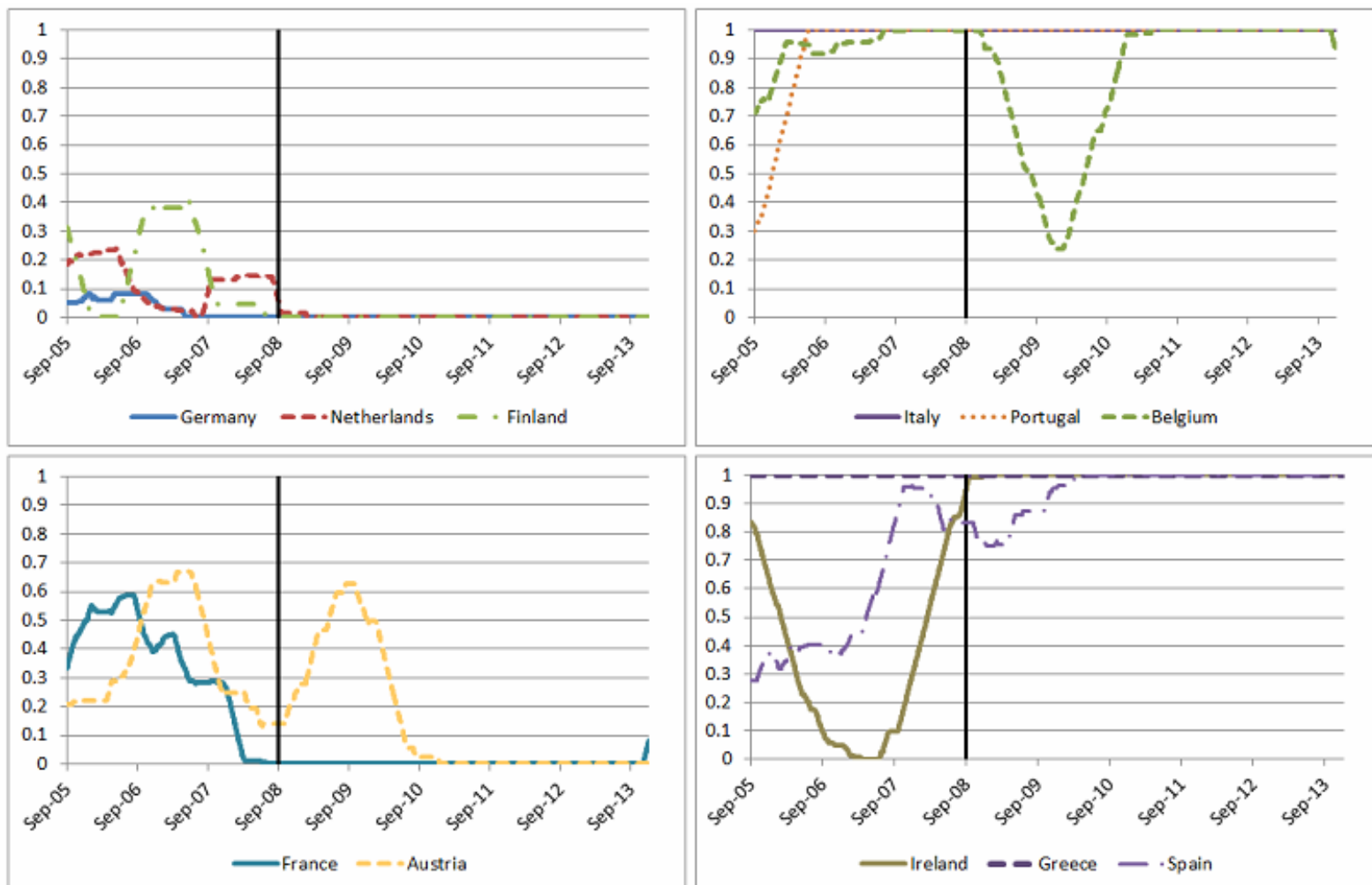

Figure V. Rolling 1 year average of days when the country-specific 10 year bond yield is above the median

These figures present the rolling 1 year average of days when the country-specific 10 year bond yield is above the Euro-zone median yield. The 10 year sovereign bond series are built using yield data from Bloomberg by considering each day the yield of the bond with the residual maturity closes to 10 years. The Lehman collapse on 15 Sep 2008 is signalled by the black vertical line. Euro-zone countries included are Germany (DE), the Netherlands (NL), Finland (FI), France (FR), Austria (AT), Belgium (BE), Italy (IT), Spain (ES), Portugal (PT), Ireland (IE), and Greece (GR). 
Appendix A. Macro and financial variables employed to obtain time varying equity betas.

\begin{tabular}{|c|c|c|}
\hline Series & Source & Unit \\
\hline \multicolumn{3}{|c|}{ Quarterly } \\
\hline Output Gap & Estimated & $\begin{array}{l}\text { (Real GDP / Real GDP Quadratic } \\
\text { Trend) - } 1\end{array}$ \\
\hline Real GDP & Eurostat & Chained 2010 Prices SWDA \\
\hline Debt/GDP & Eurostat & Ratio \\
\hline \multicolumn{3}{|c|}{ Monthly } \\
\hline Retail Sales & Eurostat & Volume SA \\
\hline Unemployment Rate & Eurostat & Harmonized Rate SA \\
\hline CPI & Eurostat & Harmonized index, $2005=100$ NSA \\
\hline Imports & Eurostat & Volume index, $2010=100$ SWDA \\
\hline Exports & Eurostat & Volume index, $2010=100$ SWDA \\
\hline Industry Production & Eurostat & Volume index, $2010=100$ SWDA \\
\hline Money supply M3 & Datastream & Volume Billion Euro \\
\hline Economic Sentiment & European Commission & Index SA \\
\hline $\begin{array}{l}\text { Rolling } 5 \text { year Correlation } \\
\text { between Industrial Production } \\
\text { Growth and Inflation }\end{array}$ & Eurostat & Percentage points \\
\hline \multicolumn{3}{|c|}{ Daily } \\
\hline 5 year CDS spread & Bloomberg & Basis Points \\
\hline Proportional Bid-Ask Spread & MTS Time Series & Basis Points \\
\hline
\end{tabular}




\section{Appendix B. ECB Unconventional Policy Measures}

The following two tables present the dates for the Announcement and LTRO dummies

Announcement dummy dates

\begin{tabular}{|c|c|}
\hline Date & Description \\
\hline 28/03/2008 & 2 supplementary 6 month LTROs. \\
\hline 04/09/2008 & Supplementary 6 month LTRO. \\
\hline 07/10/2008 & Increase in allotment amount of 6 month LTRO. \\
\hline 09/10/2008 & Fixed-rate full allotment (FRFA) procedure in the main refinancing operations (MROs) \\
\hline $13 / 10 / 2008$ & Liquidity in U.S. dollars (currency swaps with the Fed) provided at FRFA procedure. \\
\hline $15 / 10 / 2008$ & $\begin{array}{l}5 \text { supplementary } 6 \text { month LTROs. FRFA procedure in all longer-term refinancing } \\
\text { operations (LTROs). }\end{array}$ \\
\hline 05/03/2009 & $\begin{array}{l}\text { ECB will continue with the current frequency and maturity profile of supplementary } \\
\text { LTROs for as long as needed until the end of } 2009 \text {. }\end{array}$ \\
\hline 07/05/2009 & $\begin{array}{l}\text { ECB announced it would purchase euro-denominated covered bonds issued in the } \\
\text { euro area (CBPP1). } 3 \text { supplementary } 1 \text { year LTROs. }\end{array}$ \\
\hline 03/12/2009 & Supplementary 6-month LTRO. \\
\hline $10 / 05 / 2010$ & $\begin{array}{l}\text { Supplementary 6-month LTRO. Reactivation of FRFA procedure in regular longer-term } \\
\text { refinancing operations (LTROs). }\end{array}$ \\
\hline $10 / 05 / 2010$ & ECB introduces Securities Markets Programme (SMP1). \\
\hline 04/08/2011 & Supplementary 6-month LTRO. \\
\hline 08/08/2011 & SMP second phase announced (SMP2). \\
\hline 06/10/2011 & $\begin{array}{l}\text { ECB announced the second covered bond purchase programme (CBPP2). } \\
\text { Supplementary } 12 \text { month and } 13 \text { month LTRO. }\end{array}$ \\
\hline $08 / 12 / 2011$ & ECB to conduct two 3 year LTRO with provisions of repayment after one year. \\
\hline 26/07/2012 & ECB President Mario Draghi speech ("whatever it takes to preserve the euro"). \\
\hline 06/09/2012 & ECB announced Outright Monetary Transactions (OMT). \\
\hline
\end{tabular}

LTRO dummy dates

\begin{tabular}{cccc}
\hline Allotment Dates & Maturity & Allotment Dates & Maturity \\
$02 / 04 / 2008$ & 6 Months & $12 / 08 / 2009$ & 6 Months \\
$09 / 07 / 2008$ & 6 Months & $09 / 09 / 2009$ & 6 Months \\
$08 / 10 / 2008$ & 6 Months & $30 / 09 / 2009$ & 1 Year \\
$12 / 11 / 2008$ & 6 Months & $07 / 10 / 2009$ & 6 Months \\
$10 / 12 / 2008$ & 6 Months & $11 / 11 / 2009$ & 6 Months \\
$07 / 01 / 2009$ & 6 Months & $09 / 12 / 2009$ & 6 Months \\
$11 / 02 / 2009$ & 6 Months & $16 / 12 / 2009$ & 1 Year \\
$11 / 03 / 2009$ & 6 Months & $31 / 03 / 2010$ & 6 Months \\
$08 / 04 / 2009$ & 6 Months & $12 / 05 / 2010$ & 6 Months \\
$13 / 05 / 2009$ & 6 Months & $10 / 08 / 2011$ & 6 Months \\
$10 / 06 / 2009$ & 6 Months & $26 / 10 / 2011$ & 1 Year \\
$24 / 06 / 2009$ & 1 Year & $21 / 12 / 2011$ & 3 Years \\
$08 / 07 / 2009$ & 6 Months & $29 / 02 / 2012$ & 3 Years \\
\hline
\end{tabular}

